\title{
Characterization of an Oxygen Plasma Process for Cleaning Packaged Semiconductor Devices
}

Federal Manufacturing \& Technologies

B. E. Adams

KCP-613-5798

RECENED

Published November 1996

NOV 2 i 1996

OS $\mathrm{T}$ T

Final Report

Approved for public release; distribution is unlimited.

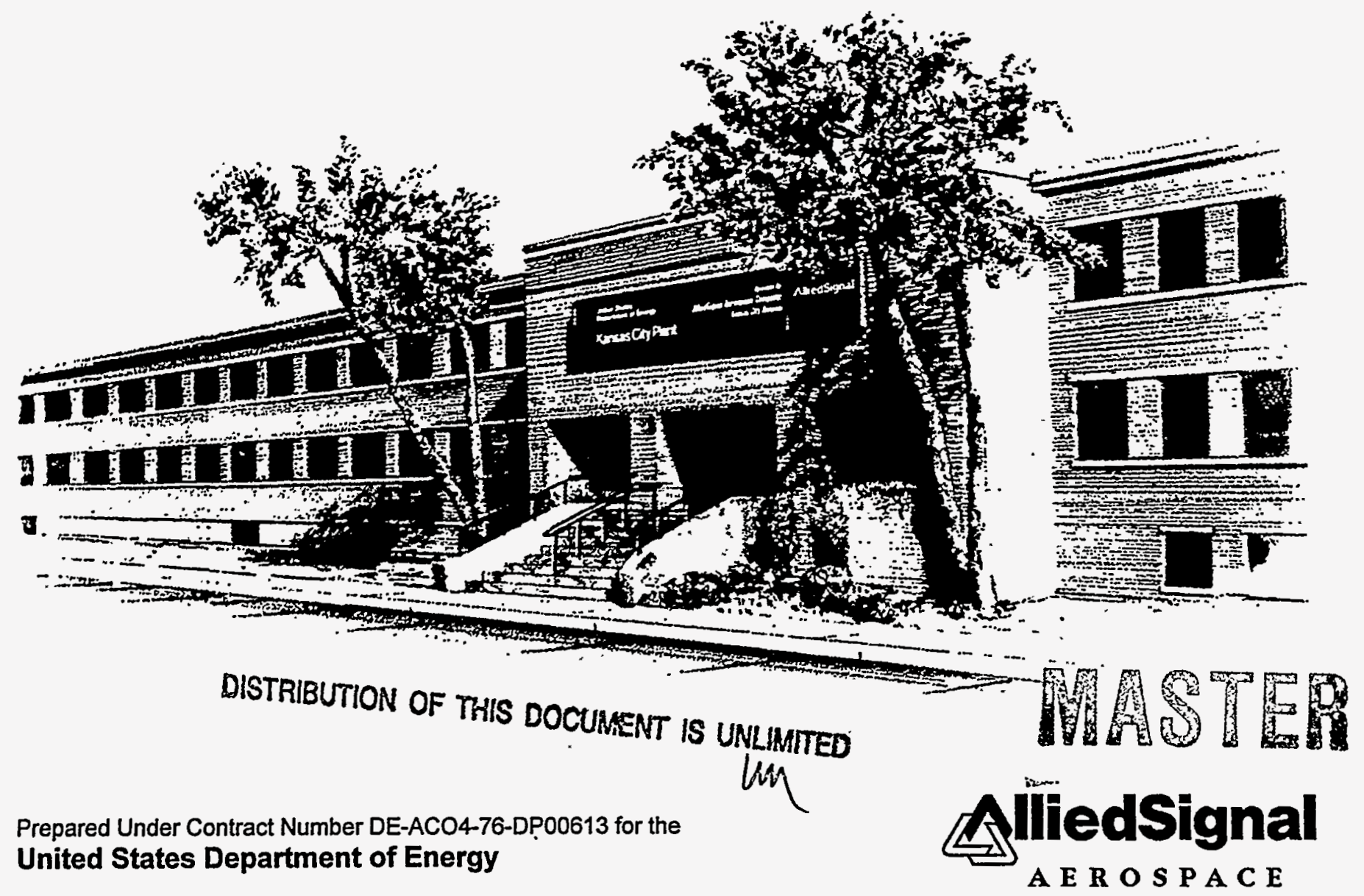




\section{DISCLAIMER}

This report was prepared as an account of work sponsored by an agency of the United States Government. Neither the United States Government nor any agency thereof, nor any of their employees, makes any warranty, express or implied, or assumes any legal liability or. responsibility for the accuracy, completeness, or usefulness of any information, apparatus, product, or process disclosed, or represents that its use would not infringe privately owned rights. Reference herein to any specific commercial product, process, or service by trade names, trademark, manufacturer, or otherwise, does not necessarily constitute or imply its endorsement, recommendation, or favoring by the United States Government or any agency thereof. The views and opinions of authors expressed herein do not necessarily state or reflect those of the United States Government or any agency thereof.

Printed in the United States of America.

This report has been reproduced from the best available copy.

Available to DOE and DOE contractors from the Office of Scientific and Technical Information, P. O. Box 62, Oak Ridge, Tennessee 37831; prices available from (615) 576-8401, FTS 626-8401.

Available to the public from the National Technical Information Service, U. S. Department of Commerce, 5285 Port Royal Rd., Springfield, Virginia 22161. 
KCP-613-5798

Distribution Category UC-706

Approved for public release; distribution is unlimited.

CHARACTERIZATION OF AN OXYGEN PLASMA PROCESS FOR CLEANING PACKAGED SEMICONDUCTOR DEVICES

\author{
B. E. Adams
}

Published November 1996

Final Report

B. E. Adams, Project Leader 


\section{DISCLAMIER}

Portions of this document may be illegible in electronic image products. Images are produced from the best available original document. 


\section{Contents}

Section

Page

Abstract

1

Summary

1

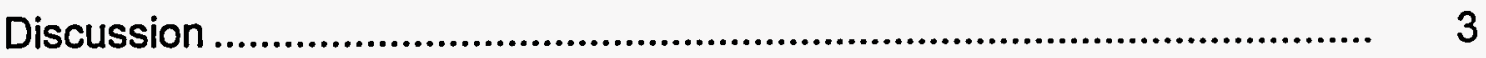

Scope and Purpose ............................................................................

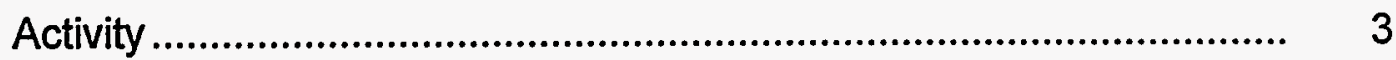

Origin of the Problem................................................................. 3

Overview of Plasma Cleaning .................................................. 4

Literature Survey ...................................................................... 9

Description of Equipment ...................................................... 13

Experimental Design .............................................................. 15

Test Method Selection for Data Collection ................................ 21

Experimental Procedure ..................................................... 21

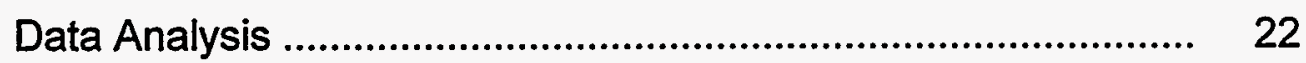

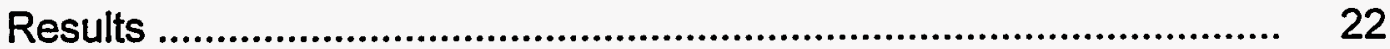

Results of the Initial Experimental Design ............................... 22

Finalized Process Characterization ........................................... $\quad 25$

Electrical Test Results ...................................................... 29 
Accomplishments .

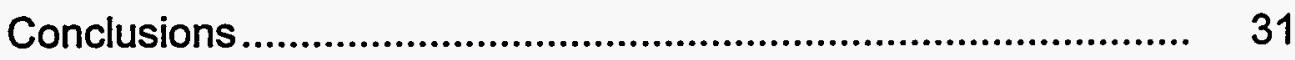

Recommendations............................................................ 32

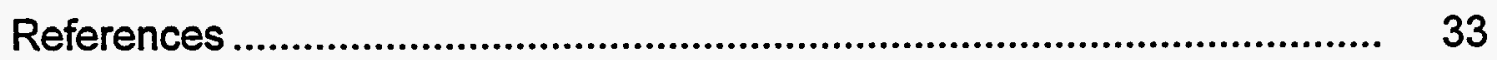

Appendices

A. Auger Analysis Data ........................................................... $\quad 35$

B. Electrical Test Data ............................................................ 48 


\section{Illustrations}

Figure

Page

1 Schematic Diagram of Plasma Cleaner.............................................. 14

2 Visual Representation of Two-Level, Three-Factor

Factorial Experiment....................................................................... 16

3 Full Factorial Design With Box-Behnken Design in Black .................. 16

4 Estimated Response Surface for Oxygen Plasma-Cleaned

Die Bond Pads

27

5 Contours of the Estimated Oxygen Plasma Cleaning

Response Surface ........................................................................... 28

A-1 Auger Spectrum of an Uncleaned Device ...................................... 40

A-2 Auger Spectrum of Device Cleaned 50 Watts, 5 Min, 0.7 Torr............ 41

A-3 Auger Spectrum of Device Cleaned 50 Watts, 15 Min, 0.7 Torr......... 42

A-4 Auger Spectrum of Device Cleaned 100 Watts, 10 Min, 0.7 Torr........ 43

A-5 Auger Spectrum of Device Cleaned 150 Watts, 10 Min, 1.1 Torr....... 44

A-6 Auger Spectrum of Device Cleaned 200 Watts, 5 Min, 0.7 Torr......... 45

A-7 Auger Spectrum of Device Cleaned 200 Watts, 15 Min, 0.7 Torr....... 46

A-8 Typical Auger Spectrum for All Cleaning Parameters After Completion of Sputtering to Verify All Carbon Has Been Removed....

B-1 Statistical Analysis of Transistor Leakage Current (ICBO) for Parts Exposed to Plasma Powers of 100, 150, and 200 Watts

B-2 Statistical Analysis of Diode Leakage Current for Parts Exposed to Plasma Powers of 100,150 , and 200 Watts 


\section{Tables}

Number

Page

1 Various Reported Plasma Cleaning Parameters and Wire Bonding Results

2 Gas Flow Rate to Chamber Pressure Correlation

3 Box-Behnken Design and Random Order of Experiment

4 Results of Auger Analysis of Aluminum Bond Pads After Oxygen Plasma Cleaning

5 Analysis of Variance for Depth of Contamination

6 Analysis of Variance After Removal of Statistically Insignificant Terms

7 Results of Auger Analysis of Aluminum Bond Pads After Oxygen Plasma Cleaning

8 Analysis of Variance for the Second Experimental Design.

26

9 Values of Actual Contamination Thickness Measurements and Calculated Contamination Thickness for the Given Cleaning Parameters

10 Average Increase in Leakage Currents for Bipolar Diodes and Transistors When Exposed to Oxygen Plasma

11 Specification Limits for Leakage Currents and Maximum Value Occurring at Each Power Setting

A-1 Auger Analysis Results for the Duplicated Box-Behnken Designed Experiment Indicating the Contamination Thickness Remaining After Cleaning at the Specified Parameters

A-2 Auger Analysis Results of the Additional Data Required for the Second Full Factorial Study. 
B-1 Electrical Tests Performed on Diodes and Transistors...................... 49

B-2 Increase in Leakage Current for Bipolar Transistors and Diodes After Oxygen Plasma Cleaning at 150 Watts, 0.7 Torr, 15 Minutes.............

B-3 Increase in Leakage Current for Bipolar Transistors and Diodes After Oxygen Plasma Cleaning at 100 Watts, 0.7 Torr, 15 Minutes..............

B-4 Increase in Leakage Current for Bipolar Transistors and Diodes After Oxygen Plasma Cleaning at 200 Watts, 0.7 Torr, 15 Minutes............. 


\begin{abstract}
The purpose of this research was to experimentally determine the operating "window" for an oxygen plasma cleaning process to be used on microelectronics components just prior to wire bonding. The process was being developed to replace one that used vapor degreasing with trichlorotrifluoroethane, an ozonedepleting substance. A Box-Behnken experimental design was used to generate data from which the oxygen plasma cleaning process could be characterized. Auger electron spectrophotometry was used to measure the contamination thickness on the dice after cleaning. An empirical equation correlating the contamination thickness on the die surface with the operating parameters of the plasma system was developed from the collected Auger data, and optimum settings for cleaning semiconductor devices were determined. Devices were also tested for undesirable changes in electrical parameters resulting from cleaning in the plasma system. An increase in leakage current occurred for bipolar transistors and diodes after exposure to the oxygen plasma. Although an increase in leakage current occurred, each device's parameter remained well below the acceptable specification limit. Based upon the experimental results, the optimum settings for the plasma cleaning process were determined to be 200 watts of power applied for five minutes in an enclosure maintained at 0.7 torr. At these settings, all measurable contamination was removed without compromising the reliability of the devices.
\end{abstract}

\title{
Summary
}

The purpose of this project was to experimentally determine the operating "window" for an oxygen plasma cleaning process to be used on microelectronics components assembled at AlliedSignal Federal Manufacturing \& Technologies (FM\&T). The plasma cleaning process was to be performed just prior to bonding wires to the semiconductor devices to improve the yield and reliability of the bonding process. The process was being developed to replace one that used vapor degreasing with trichlorotrifluoroethane, an ozone-depleting substance. A statistical approach, employing design of experiment techniques, was used to correlate the operating conditions to the contamination thickness on the device surface after cleaning. The contamination thickness was measured using Auger spectroscopy, an analytical technique developed to determine the elemental composition of the top 5-50 angstroms of an electrically conductive solid. The effect of oxygen plasma exposure on the electrical parameters of the devices was also measured using a Lorlin Impact IV electrical tester.

The equipment being characterized in this study was a Branson/IPC barrel plasma cleaner, model S2005T-11020SC with a PM119 if generator. The initial results from the Box-Behnken study showed that the power setting and the cleaning time of the plasma process were the most significant factors for removing organic contamination. Changes in pressure did not significantly affect the removal of contamination from the die surface. The contamination 
thickness ranged from a high of $240 \AA$ when cleaned at 50 watts for five minutes at a pressure of 0.7 torr to a low of $0 \AA$ after cleaning at 200 watts for 5 minutes at 0.7 torr.

A correlation between the process parameters and the remaining contamination thickness was established from the results of a second full factorial experimental study which varied the time and power settings. The correlation equation (1) shown below is for the range of power between 50 and 200 watts and cleaning times of 5 to 25 minutes.

$$
Y_{\text {mod }}=435.083-3.60081 X_{1}-8.45127 X_{2}+0.0071838 X_{1}^{2}+0.0413479 X_{1} X_{2}
$$

At the beginning of this project it was believed that a change in the electrical parameters of the devices would establish the upper bound on the power and time allowed to clean the semiconductor devices. The purpose of the project was to map the contamination thickness as a function of power, time, and pressure with the upper constraint set by the change in leakage current of the semiconductor devices. Then the results of the plasma cleaning process would be compared to the results of the current CFC vapor degreasing process in order to validate the decision to replace the CFC degreasing process. It was found that the change in the leakage current stayed well below the specification limits through the entire range of power and time studied. The increase in leakage current of bipolar transistors and diodes when exposed to oxygen plasma was measurable. However, the change was associated with the fact of plasma exposure, not with the extent of the exposure. Contrary to the theoretical expectation that plasma exposure would alter the electrical properties proportionally with the power and time, it was concluded that the relationship between electrical performance and extent of plasma exposure was unproven in the range studied.

Since the degradation of electrical performance proved not to be a constraint, the solution for AlliedSignal was to replace the solvent vapor degreasing process with the oxygen plasma process. The oxygen plasma cleaning parameters should be set at 0.7 torr, between 150 and 200 watts, and 5 to 10 minutes for production operation. At these settings AlliedSignal gains a much improved cleaning method that yields cleaner surfaces at 1/6 of the time of the CFC vapor degreasing process. The reduced processing time for cleaning becomes a cost savings to the division, because reducing the flow time of the product reduces the cost of manufacturing. Based on a production level of 300 pieces per month, an estimated annual cost savings of $\$ 2000$ could be achieved by changing the cleaning process.

Based on the results of this study, it was recommended that AlliedSignal immediately implement the use of oxygen plasma cleaning process to prepare semiconductor devices for wire bonding. This recommendation was accepted by AlliedSignal; the plasma cleaning process is now in use on test product. 


\section{Discussion}

\section{Scope and Purpose}

The purpose of this project was to experimentally determine the operating "window" for an oxygen plasma cleaning process to be used on microelectronics components assembled at AlliedSignal Federal Manufacturing \& Technologies (FM\&T). The plasma cleaning process was to be performed just prior to bonding wires to the semiconductor devices to improve the yield and reliability of the bonding process. The characterization of the plasma cleaning process was to be undertaken to answer two main questions after cleaning:

- Is the surface clean enough to reliably attach a wire?

- Are the electrical parameters of the devices cleaned still within the specification limits?

A statistical approach, employing design of experiment techniques, was to be used to correlate the operating conditions to the contamination thickness on the device surface after cleaning. The effect of oxygen plasma exposure on the electrical parameters of the devices was also to be measured. The contamination thickness was to be measured using Auger spectroscopy, an analytical technique used to determine the elemental composition of the top 5-50 angstroms of an electrically conductive solid. Devices were to be electrically tested before and after plasma cleaning with a Lorlin Impact IV tester to measure any change in voltage or leakage current of bipolar transistors and diodes. The optimum operating conditions for the oxygen plasma cleaning process was to be selected based upon the minimization of residual contamination remaining on the surface of the microcircuit constrained by the electrical performance of the devices.

\section{Activity}

\section{Origin of the Problem}

Since the late 1980s, American industry has focused on environmentally conscious manufacturing. The mandated phase-out of ozone-depleting chlorofluorocarbons (CFCs) and chlorohydrocarbons (CHCs), the increased regulations on hazardous waste, and the overall American attitude to "clean up" manufacturing have forced industry to look for environmentally friendly processes to replace the current "dirty" processes. AlliedSignal FM\&T has taken hazardous waste reduction very seriously over the past seven years and has reduced the usage of CFCs by $97 \%$. However, the remaining $3 \%$ included CFC usage in the microelectronics department. In the microelectronics department, trichlorotrifluoroethane (CFC-113) has been used to clean hybrid microcircuits between processing steps, the most critical being just before wire bonding. The low toxicity of the solvent, good degreasing ability, and component compatibility made it an exceptionally good choice for the microelectronics industry. However, due to its detrimental effects on the ozone and eventual phase-out, an alternative cleaning process was to be evaluated. Oxygen plasma cleaning was chosen as the process to evaluate to replace the current CFC cleaning process. 
Plasma cleaning was developed in the 1960 s as a surface treatment process prior to bonding, encapsulating, and potting where surface conditions are important. Plasmas have also been used to decompose hazardous organic materials, to restore and conserve ancient artifacts, and to enhance chemical reactions such as the polymerization of hexamethyldisiloxane. Plasma cleaning (etching) was first used in the electronic industry to remove photoresist from wafers during wafer fabrication. The ability of a plasma to selectively etch without requiring hazardous chemicals or producing any hazardous waste makes it a very important process for the 1990s. Carbon dioxide and water are the main by-products of oxygen plasma cleaning.

Prior to bringing this process into production, a full evaluation of the process variables and their effect on the product must be performed. In this study, the product was class S military electronic devices. These devices must function electrically within tight limits for a 30 -year period. Therefore, characterization of the plasma process was critical to determine if the mechanical and electrical requirements of the device can be met and maintained after plasma cleaning. An effective and efficient method for characterizing a process when the actual chemical mechanism is too complex to express mathematically is to use an experimental design that leads to estimates of the process response over an entire range of critical variables. This method, known as response surface modeling, is a statistical approach to develop an empirical mathematical expression from measurements of the process responses at a specified set of conditions. The expression is used to correlate the measured dependent variable to the independent process parameters. In order to develop an experimental procedure that will accurately reflect the process responses, a good understanding of the cleaning process is required. Otherwise, the experimenter may miss important process variables, resulting in a poorly controlled process.

\section{Overview of Plasma Cleaning}

A plasma is defined as a partially ionized gas containing an equal number of positive and negative charges, as well as a large number of nonionized gas particles, some of which are in an excited or free radical state. Although the totality of plasma cleaning is very complex, the basic concept of utilizing a plasma for cleaning is straightforward. A gas is purged into an evacuated chamber and passed through an electric field. The electric field strips electrons from a small fraction of the molecules, putting them into a charged, reactive state. The free electrons are accelerated by the electric field and collide with other gas molecules, knocking more electrons free and creating more reactive species. Some of the reactive molecules will collide with the hybrid microcircuit located in the vacuum chamber and react with other molecules on its surface. The reaction between the reactive plasma molecules and the molecules on the microcircuit surface produces a gaseous by-product which leaves the surface of the microcircuit. The surface reaction rate and reaction by-products are strongly affected by the choice of plasma gas. An argon plasma typically reacts by momentum transfer, i.e., physically knocking the surface molecules off the hybrid by brute force. Oxygen plasma, on the other hand, will chemically react with an organic surface material, breaking it down to gaseous $\mathrm{CO}_{2}$ and $\mathrm{H}_{2} \mathrm{O}$. 
There are two areas of importance in plasma etching chemistry:

- The generation of the reactive plasma, and

- The reaction steps involved to remove contamination from the microcircuit surface.

These areas, discussed in the next two sections, can best be described by the kinetic gas theory developed by Maxwell and Boltzman.

\section{Generation of Reactive Plasma}

The generation of a reactive gas plasma can be described by the kinetic gas theory. In summary, the kinetic gas theory states:

1. A gas consists of molecules that have the mass $m$.

2. The molecules are in continual random chaotic motion at various velocities and in all directions.

3. The random motion will result in collisions between molecules and between a molecule and the container wall. These collisions are either elastic or inelastic. Elastic collisions are ones in which there is an interchange of kinetic energy only. The molecules can be assumed to be solid spheres. Inelastic collisions are ones in which the molecules' internal energy and kinetic energy change. Forms of internal energy would be electronic excitation, ionization, and bond vibration.

4. The gases are assumed to be ideal, and the mean distance between molecules is much greater than their diameter.

5. No appreciable forces exist between the molecules or between a molecule and the wall of the container except during collision. Therefore, the flight path between collisions is assumed to be a straight line.

The key to the success of plasma cleaning is related to the frequency and number of inelastic collisions between electrons and molecules. This is tied directly to the velocity distribution of the electrons. The majority of collisions which occur are elastic where virtually no exchange of energy from the electron to the molecule takes place. An analogy would be to throw a pingpong ball against a bowling ball. The ping-pong ball would bounce off the bowling ball which would remain stationary. But when an electron has a sufficient amount of kinetic energy, it can penetrate the molecule and cause ionization, excitation, or form radicals. Hollahan reported that Meyer (1969) determined the electron energy required in an oxygen plasma for inelastic collisions of electrons with oxygen. ${ }^{1}$ According to Meyer, singlet oxygen, $O$, begins to form in a plasma when the electron energy is above one electron volt. ${ }^{2}$ The formation of radicals occurs when the electron energy rises above four electron volts. These levels of electron energy are acquired by the application of an external electric field. The introduction of an electric field increases the average electron velocity and increases the number of inelastic collisions. 
The Boltzmann equation, as given by Hollahan and Bell (1974) and shown in equation (2), is used to derive the electron-velocity distribution function for a gas. ${ }^{1}$

$$
\partial f / \partial t+v \cdot \nabla_{r} f+e E / m \cdot \nabla_{v} f=(\partial f / \partial t)_{\text {coll }}
$$

The first term on the left-hand side of (2) gives the local variation of the distribution function with time. The second term describes the variation in the distribution function resulting from electrons streaming in and out of a given volume element. The third term is the variation of the distribution function resulting from an applied electric field, $\mathrm{E}$, acting on the electrons. The single term on the right-hand side of (2) accounts for the net transfer of electrons from the differential volume by the mechanism of binary collisions between electrons and molecules, ions, and other electrons. The electron-velocity distribution plays a central role in defining the physical properties of a plasma. From it are derived the electron-energy distribution, the average electron energy, the electron-transport properties, and the rate constants for reactions involving electron-molecule collisions. The shape of the distribution function depends upon the magnitude of the applied electric field and the nature of the elastic and inelastic interactions which the electrons undergo.

Maxwell derived the electron velocity distribution for gases not being influenced by an external electric field. In his derivation, the assumption of thermal equilibrium was understood. Molecules are moving at random velocities that can vary from zero to infinity. Because of the velocity variability, there is a probability density function, $f(v)$, that represents the molecular velocity distribution. The fraction of molecules having velocities within the range $v$ to $v+d v$ is then $f(v) d v$. The probability function for one dimension as shown in equation (3).

$$
f\left(v_{x}\right) d v_{x}=\exp \left(-m v_{x}^{2} / 2 k T\right) d v_{x} /(2 p k T / m)^{1 / 2}
$$

Since molecular motion is random, and the orientation of the coordinate system is arbitrary, the probabilities in each direction are identical. Therefore, the fraction of molecules with velocities in the range of $v$ to $v+d v$ in three-dimensional space is given by equation (4) and is known as a Maxwellian distribution.

$$
f(v) d v=(m / 2 \pi k T)^{3 / 2}\left(4 \pi v^{2}\right) \exp \left(-m v^{2} / 2 k T\right) d v
$$

From this velocity distribution the most probable speed, $v_{p}$, is obtained as shown in equation (5) by setting $\mathrm{df}(\mathrm{v}) / \mathrm{dv}$ equal to zero.

$$
v_{p}=(2 k T / m)^{1 / 2}=(2 R T / M)^{1 / 2}
$$

Once the velocity distribution is known, the number of collisions per unit time per unit area may be calculated. The number of collisions is the basis for determining the surface reaction rate on the microcircuit. To calculate the number of collisions, consider a cylindrical volume of gas with the bottom of the cylinder against the wall with an area $A$. The molecules within this volume have components of velocities in the $x, y$, and $z$-directions, and some will strike area $A$ during a given amount of time dt. The volume of the cylinder is equal to the product of the area and the height, given by $\mathrm{vz} d t$. If $r$ is the concentration of molecules, the number of molecules in the 
cylinder is $\rho A v_{z}$ dt. Multiplying the number of molecules in the cylinder with the probability density, $f\left(v_{x}, v_{y}, v_{z}\right)$ and integrating over all values of the component velocities yields the number of collisions, $z$, per unit area per unit time given by equation (6).

$$
z=\rho \iint v_{z} f\left(v_{x}\right) f\left(v_{y}\right) f\left(v_{z}\right) d v_{x} d v_{y} d v_{z}
$$

or

$$
z=\rho(m / 2 \pi k T)^{1 / 2} \int v_{z} \exp \left(-m v_{z}^{2} / 2 k T\right) d v_{z}=\rho v / 4
$$

A more detailed derivation for all the above equations can be found in Alberty and Daniels $(1980){ }^{3}$

When an external electric field is introduced to the gas, the electron velocity distribution changes shape. The solution to the Boltzmann equation with low electric field strengths, where inelastic collisions are neglected, is a Margenau or Druyvesteyn distribution. However, when inelastic collisions can no longer be considered negligible, as is the case for plasma cleaning, the Boltzmann equation becomes quite complex; and it is no longer feasible to provide an analytical solution. The next step is to turn to a numerical solution or to determine to what degree a Maxwellian or other known distribution might be used as an approximation.

\section{Surface Reaction Propagation}

Plasma cleaning (etching) relies on the chemical combination of a solid surface material with an active gaseous species produced in the plasma. In this project, the plasma is used to convert molecular oxygen, which does not react with solid carbon at room temperature, into radicals which will readily react with the organic residue on the dice surfaces. A volatile product is created and removed by the vacuum system. The reaction events that take place during etching of the organic material on the substrate surface include

1. Diffusion of the reactive plasma species to the material surface being cleaned,

2. Absorption of the species onto the surface,

3. Reaction between absorbed species and surface molecules producing a volatile compound,

4. Desorption of the reaction product from the surface,

5. Diffusion of product back into bulk plasma, and

6. Removal of the diffused compound from the reaction chamber by the vacuum pump.

All through the course of this reaction, the surface is continually bombarded by ions, radicals, electrons, and photons, releasing the needed energy for the surface reactions to occur. 
As previously mentioned, plasma cleaning was first used in electronics to remove photoresist materials from silicon wafers. Photoresist is an organic compound consisting mainly of carbon and hydrogen. An oxygen plasma was selected to "strip" the material from the silicon by converting solid carbon to gaseous carbon monoxide and carbon dioxide. The hydrogen from the photoresist reacted with the oxygen to produce water vapor. The creation of oxygen radicals and ions is achieved by electron impact with gaseous oxygen and the subsequent dissociation of the oxygen molecule. Hollahan and Bell (1974) list 34 different reactions of oxygen in a glow discharge plasma. ${ }^{1}$ The most important of these reactions for plasma etching of organic material are shown below.

Ionization

$$
\begin{aligned}
& e+\mathrm{O}_{2} \rightarrow \mathrm{O}^{+}+2 e \\
& e+\mathrm{O} \rightarrow \mathrm{O}^{+}+2 e
\end{aligned}
$$

Dissociative ionization

$$
e+\mathrm{O}_{2} \rightarrow \mathrm{O}^{+}+\mathrm{O}
$$

Dissociative attachment

$$
\begin{aligned}
& e+\mathrm{O}_{2} \rightarrow \mathrm{O}^{-}+\mathrm{O} \\
& e+\mathrm{O}_{2} \rightarrow \mathrm{O}^{-}+\mathrm{O}^{+}+e
\end{aligned}
$$

Dissociation

$$
e+\mathrm{O}_{2} \rightarrow 2 \mathrm{O}+e
$$

The reaction rate on the substrate surface is a function of the concentration of reactive species. In turn, the concentration of reactive species is dependent upon the electric field strength. As the field strength is increased, the concentration of reactive species increases. However, if the field strength is too high, too much energy may be released to the substrate surface, breaking electrons from the crystal lattice. This would leave holes, which under the right conditions could migrate to the electrically active areas of the device and cause electrical failure of the device.

Although many macroscopic parameters can be controlled, such as type of feed gas, power, pressure, and gas flow rate, the precise effect of making any changes in these parameters is not well understood. In fact, a change in a single macroscopic parameter typically alters two or more basic plasma parameters, and that affects the overall removal rate of contamination on the die surface. This makes process development in plasma systems a challenge and necessitates the use of factorial experimental design techniques. To assist in designing this experiment, a literature search was performed to screen the number of variables to include in this study and to establish a base point from which to evaluate the oxygen plasma cleaning process for packaged semiconductor devices. 


\section{Literature Survey}

The objective of the literature search was to determine the extent to which plasma cleaning of hybrid microcircuits had been developed. Specific issues of interest were

- the types of etch gases used,

- the significant variables studied,

- the range of each variable studied, and

- the effect of exposing semiconductor devices to a plasma.

The information gathered in these four areas determined which variables, including range, should be studied in a designed experiment and illuminated the major areas of concern. This effort greatly reduced the number of experiments required to locate the optimum operating parameters. The Engineering Index Data Base was searched using the following key words and phrases: plasma etching, plasma cleaning, microelectronics, hybrid microcircuits, and design of experiment. The information collected in the literature search was divided into two categories: operating variables and potential concerns. These topics are discussed in the next two sections.

\section{Operating Variables}

Numerous studies have been conducted to measure plasma cleaning's effectiveness in reducing wire bond failures on hybrid microcircuits. These studies were conducted because a major cause of failure in hybrid manufacturing was wires failing to stick to the components when being bonded. In order to create a successful wire bond, an intermetallic contact between the pads on the hybrid and the wire must be achieved. An adequate contact can be produced only when all surfaces are extremely clean. It has been documented that low levels of contamination can greatly reduce wire bond reliability. Graves (1983) demonstrated that a very thin contamination layer on the device surface will inhibit wire bonding. ${ }^{4}$

The primary sources of contamination that inhibit wire bonding are organic residues (either photoresist or tape adhesive) left after wafer fabrication processes plus more organic residue from adhesives used to attach die to the package. Khan, Tarter, and Fatemi (1987) investigated contamination of bond pads by thermal outgassing of organic adhesives and found that an organic residue 80 to 200 angstroms thick was deposited over the bond pads during the adhesive cure cycle. ${ }^{5}$ Wire bonding to these uncleaned pads resulted in $100 \%$ bond failure, but after a $\mathrm{N}_{2} / \mathrm{O}_{2}$ plasma cleaning step, the failures were reduced by an order of magnitude (still having $10-15 \%$ failure rate). In that investigation no effort was made to characterize the plasma cleaning process. Their main emphasis was comparing contamination left by various organic adhesives. 
The low level of contamination left by epoxy outgassing is virtually impossible to remove using standard organic solvent methods. Thus a molecular level of cleaning is necessary to remove the surface contamination on the hybrids. Only one bondability study was found during this literature search, and it was completed by Weiner (1983). ${ }^{6}$ The study directly compared oxygen plasma cleaning and solvent cleaning. Weiner found that solvent treatment was ineffective for removal of photoresist or epoxy contaminant. Oxygen plasma, on the other hand, was found to be an acceptable technique for restoring shear strengths of gold ball bonds from gold or aluminum metallization. Kenison (1984) compared oxygen plasma with solvent cleaning on incoming die for epoxy bleed removal. ${ }^{7}$ She verified Weiner's conclusion that oxygen plasma cleaning is effective and that solvent cleaning is not helpful in removing the microlayers of general organic contaminants. Kenison found oxygen plasma cleaning decreased the number of ball bond failures by $74 \%$ over solvent cleaning.

Table 1 compares various plasma cleaning processes studied by different investigators and their reported effect on wire bonds and die. The table illustrates that a variety of gases, power, pressure, and time settings produced satisfactory cleaning for bonding. However, only one of these studies addressed the potential detrimental electrical effects on the die from plasma cleaning. Kim was the only investigator in that group who looked at effects of the plasma cleaning process on the electrical parameters of the die. ${ }^{8}$ His observations are discussed in the next section.

Although some experimentation was done by all investigators to find the optimum parameters for plasma cleaning, none of the investigators fully developed a response surface for their process. Daniel et al (1988) and Jenkins et al (1986) discussed an experimental design based on response surface methodology to develop a process window for plasma etching. ${ }^{9.10}$ Daniel used this methodology to investigated uniformly etching a top layer without damage to an underlayer, and Jenkins evaluated polysilicon etching.

As can be seen in Table 1, the literature survey was instrumental in determining which variables and their ranges to investigate. From the table it can be seen that five primary variables exist: power, gas, pressure, gas flow rate, and time. Oxygen had previously been selected as the gas, and the chamber pressure is dependent on the gas flow rate and vacuum pump capability. Since the vacuum pump on our equipment did not have a throttling valve, and one was not to be installed, the gas flow rate and chamber pressure was reduced from two to one variable. 
Table 1. Various Reported Plasma Cleaning Parameters and Wire Bonding Results

\begin{tabular}{|c|c|c|c|c|c|c|}
\hline $\begin{array}{l}\text { If Power } \\
\text { (Watts) }\end{array}$ & Gas & $\begin{array}{l}\text { Pressure } \\
\text { (Torr) }\end{array}$ & $\begin{array}{l}\text { Gas Flow. } \\
\text { Rate } \\
\text { (cc/min) }\end{array}$ & $\begin{array}{l}\text { Time } \\
\text { (Min) }\end{array}$ & Effect on Bonds & Reference \\
\hline 300 & $\overline{\mathrm{O}_{2}}$ & unknown & 300 & 10 & $\begin{array}{l}\text { Reduced } \\
\text { corrosion }\end{array}$ & $\begin{array}{l}\text { lannuzzi } \\
(1981)^{11}\end{array}$ \\
\hline 100 & $\mathrm{O}_{2}$ & 0.5 & unknown & 10 & $\begin{array}{l}\text { Increased ball } \\
\text { shear strength }\end{array}$ & $\begin{array}{l}\text { Weiner } \\
(1983)^{6}\end{array}$ \\
\hline 50 & $\mathrm{O}_{2}, \mathrm{Ar}$ & 0.5 & unknown & 30 & $\begin{array}{l}\text { Cleaned ceramic } \\
\text { substrate }\end{array}$ & $\begin{array}{l}\text { Mead } \\
(1978)^{12}\end{array}$ \\
\hline $50-150$ & $\mathrm{O}_{2}, \mathrm{Ar}$ & unknown & 130 & $2-10$ & $\begin{array}{l}\mathrm{O}_{2} \text { increased } \\
\text { reliability, } \mathrm{Ar} \\
\text { removes } \mathrm{AgO}_{2}\end{array}$ & $\begin{array}{l}\text { Bonham } \\
(1979)^{13}\end{array}$ \\
\hline $50-300$ & $\overline{\mathrm{O}_{2}}$ & $1-2$ & unknown & 10 & $\begin{array}{l}\text { Increased bond } \\
\text { reliability }\end{array}$ & $\begin{array}{l}\text { White } \\
(1982)^{14}\end{array}$ \\
\hline$<300$ & $\begin{array}{l}\mathrm{O}_{2}, \mathrm{Ar}, \\
\mathrm{N}_{2}\end{array}$ & 0.25 & unknown & 60 & $\begin{array}{l}\text { Increased } \\
\text { bondability }\end{array}$ & $\begin{array}{l}\text { Graves } \\
(1983)^{4}\end{array}$ \\
\hline 100 & $\begin{array}{l}2 \% \mathrm{O}_{2} \\
98 \% \mathrm{Ar}\end{array}$ & unknown & unknown & $3-5$ & $\begin{array}{l}\text { Increased } \\
\text { bondability, } \\
\text { reliability }\end{array}$ & $\begin{array}{l}\text { Kenison } \\
(1984)^{7}\end{array}$ \\
\hline $75-100$ & $\mathrm{Ar}$ & 0.2 & 113,000 & $5-10$ & $\begin{array}{l}\text { Increased } \\
\text { bondability }\end{array}$ & $\begin{array}{l}\text { Buckles } \\
(1987)^{15}\end{array}$ \\
\hline 220 & $\mathrm{O}_{2}$ & 1 & 600 & $10-15$ & $\begin{array}{l}\text { Increased } \\
\text { bondability }\end{array}$ & $\begin{array}{l}\text { Nesheim } \\
(1984)^{16}\end{array}$ \\
\hline 200 & $\overline{\mathrm{O}_{2}}$ & 0.225 & unknown & $8-10$ & $\begin{array}{l}\text { Electrical } \\
\text { parameters within } \\
\text { spec. }\end{array}$ & $\begin{array}{l}\text { Kim } \\
(1989)^{8}\end{array}$ \\
\hline 100 & $\overline{\mathrm{O}_{2}}$ & 0.7 & 300 & 30 & $\begin{array}{l}\text { Solved bonding } \\
\text { problems of beam } \\
\text { lead and } \\
\text { capacitors }\end{array}$ & $\begin{array}{l}\text { Fritsche } \\
(1990)^{17}\end{array}$ \\
\hline
\end{tabular}

\section{Potential Concerns}

Adding a plasma cleaning process to the manufacturing of hybrids raises three areas of concern:

- Changes to thin and thick film printed resistors on the hybrid's substrate,

- Reduction in shear strength of silver-filled epoxies, and

- Change in electrical parameters of the silicon devices. 
Kenison studied the effect of oxygen plasma at $100 \mathrm{~W}$ for 3 minutes on thick film resistors. ${ }^{7}$ She found a few of the resistor values drifted, but they changed by less than $1 \%$. Fritsche (1991) studied oxygen plasma cleaning of Ti/Pd and tantalum nitride trimmed and untrimmed thin film resistor. ${ }^{18}$ There was some change in resistance when cleaned for up to one hour at $150 \mathrm{~W}$ and 0.700 torr, but values remained within the stability specification of $-0.05 \%$ and $+0.2 \%$. Based on these two studies, changes in resistor values are small and would not eliminate the use of oxygen plasma cleaning.

White (1982) showed that although oxygen plasma would oxidize the silver in the conductive epoxies, it had no effect on the material's shear strength or volume resistance. ${ }^{14}$ This was confirmed by Kension and Buckles. ${ }^{7,15}$ The epoxy was clearly attacked by the oxygen plasma on the surface, but with the short exposure to the plasma, the bulk of the material was unaffected. The oxidation of the silver was only a surface effect and did not progress more than a few angstroms.

There have been reports that some special CMOS devices may display increased threshold voltages after plasma cleaning. Degradation of bipolar devices has also been reported. Buck (1988) found that a DMOS switch array was sensitive to plasma cleaning. ${ }^{19}$ He believed it was due to the thin oxide layer. Problems on CMOS, DMOS, and bipolar devices are presumed to be the result of the energetic gaseous ions impacting on the device insulators (oxide and nitrides). This can generate electron-hole pairs. Harman (1991) states the threshold for ionization of an electron-hole pair in silicon dioxide is $9 \mathrm{eV} .^{20}$ Thus, any ion, electron, or photon which has energy greater than $9 \mathrm{eV}$ and collides with an oxide surface can create an electronhole pair in the oxide. Depending on plasma and surface conditions (secondary emission from the oxide and trapping near the oxide surface region), the oxide surface can charge either positively or negatively. In either case, because electrons are mobile in silicon dioxide and holes have long life times, they may drift through the oxide layer to the oxide-silicon interfaces. Holes trapped at the silicon interface create a positive charge, which can invert the silicon under the oxide. In MOS circuits, inversion of that surface can result in loss of isolation between adjacent transistors, resulting in circuit failure. Electron and/or hole drift from the top surface of the chip will not normally result in a charge buildup under the gate oxide, but rather in a charge buildup under the field oxide. In modern bipolar circuits, the vertical transistors are oxideisolated. Thus, charge in the field oxide can short the emitter to the collector. The introduction as well as subsequent migration of electrons or holes into the device insulators is known as radiation damage.

Supporting data on radiation damage was collected by Kim (1989), who found changes in electrical characteristics of BIFET OP AMPs due to oxygen and argon plasma cleaning. ${ }^{8}$ Exposure to oxygen plasma for 16 minutes at $100 \mathrm{~W}$ and 0.225 torr increased the bias current from $6 \mathrm{pA}$ to $38 \mathrm{pA}$. However, this remained well below the $100 \mathrm{pA}$ specification limit. Argon had a larger impact on the bias current, raising it from 5 to $110 \mathrm{pA}$ after eight minutes at $50 \mathrm{~W}$ and 0.225 torr. 
Frieser found that oxygen plasma cleaning of bare silicon substrates which had been doped with boron had a resistance change occur in the base region of transistors. ${ }^{21}$ The resistance change was linked with a boron displacement from silicon lattice sites. The plasma operating condition that caused this phenomenon were 350 if power, $500 \mathrm{~mm}$ pressure, flow rate of $500 \mathrm{sccm}$, and time of 35 minutes. However, Frieser discovered that annealing the wafers at $300^{\circ} \mathrm{C}$ for 10 minutes restored the resistance to its original value.

Harman suggests that radiation damage can possibly be avoided by reducing the if power and cleaning time. ${ }^{20}$ Harman claims using an oxygen plasma with $75 \mathrm{~W}$ of if power for 3 to 4 minutes may avoid device damage and sufficiently clean the dice. He goes on to say that If powers above $300 \mathrm{~W}$ can be detrimental because of excessive heating of the samples, potentially sputtering off the metallization and changing the electrical characteristics of the devices due to radiation damage. However, Ryden (1987) was unable to detect any gate oxide damage after barrel plasma treatment in nitrogen at $13.56 \mathrm{MHz}, 150 \mathrm{~W}$ for $7 \mathrm{~min}^{22}$

All authors agree that electrostatic discharge damage is not possible in a barrel etching system running at $13.56 \mathrm{MHz}$. Ryden states that at $13.56 \mathrm{MHz}$ the charge that can be transferred to the wafer is so small that it is unlikely the gate will reach a level where electrical breakdown will occur. ${ }^{22}$ With high frequency (13.56 MHz), ions will not follow the rapidly alternating field. The electrons can because of their low mass. In the worst case, ions will diffuse toward the cathode during the entire cycle whereas electrons will only arrive during an extremely short period to neutralize the positive charge. Also, Singer (1987) claimed that wafers stripped in a barrel system with either a quartz boat or in an etch tunnel showed no ill effects from the process. ${ }^{23}$

The conclusion drawn from the study of the literature was that an oxygen plasma cleaning process for semiconductor packaging should be characterized. Although changes in some electrical parameters of the devices cleaned were found, it was suggested that minimizing the exposure power and time would minimize the change in parameters. Therefore, the primary variables investigated in this project were time, from 5 to 25 minutes; power, from 50 to 200 watts; and pressure, from 0.3 to 1.1 torr. These variables and their ranges were chosen based upon the studies conducted by the other investigators.

\section{Description of Equipment}

The "recipe" developed for plasma cleaning is strongly affected by the particular choice of equipment. One recipe cannot be used universally among different plasma cleaners with an expectation of the same results. Therefore, it is important to describe the type and configuration of equipment being characterized accurately. In order to measure the ability of the plasma cleaning equipment, two pieces of diagnostic equipment were to be used to analyze the results of the characterization experiments. The diagnostic equipment chosen to evaluate this plasma cleaner were an Auger electron spectrophotometer and a Lorlin Impact IV electrical tester. The description of these instruments and their operation are given in appendices $A$ and $B$, respectively. 
A typical plasma cleaning system runs at low temperature $\left(25-150^{\circ} \mathrm{C}\right)$ and low pressure ( 0.225 to 1 torr). The etch gas is bled into a continuously evacuated quartz reaction chamber through a needle valve at flow rates of 50 to 500 standard cc/min. The etch gas is excited by inductively or capacitiveiy coupled radio frequency (rf) power, usually at $13.56 \mathrm{MHz}$. The equipment being characterized in this study was a Branson/IPC barrel plasma cleaner, model S2005T-11020SC with a PM119 rf generator. A functional block diagram of the equipment is shown in Figure 1.

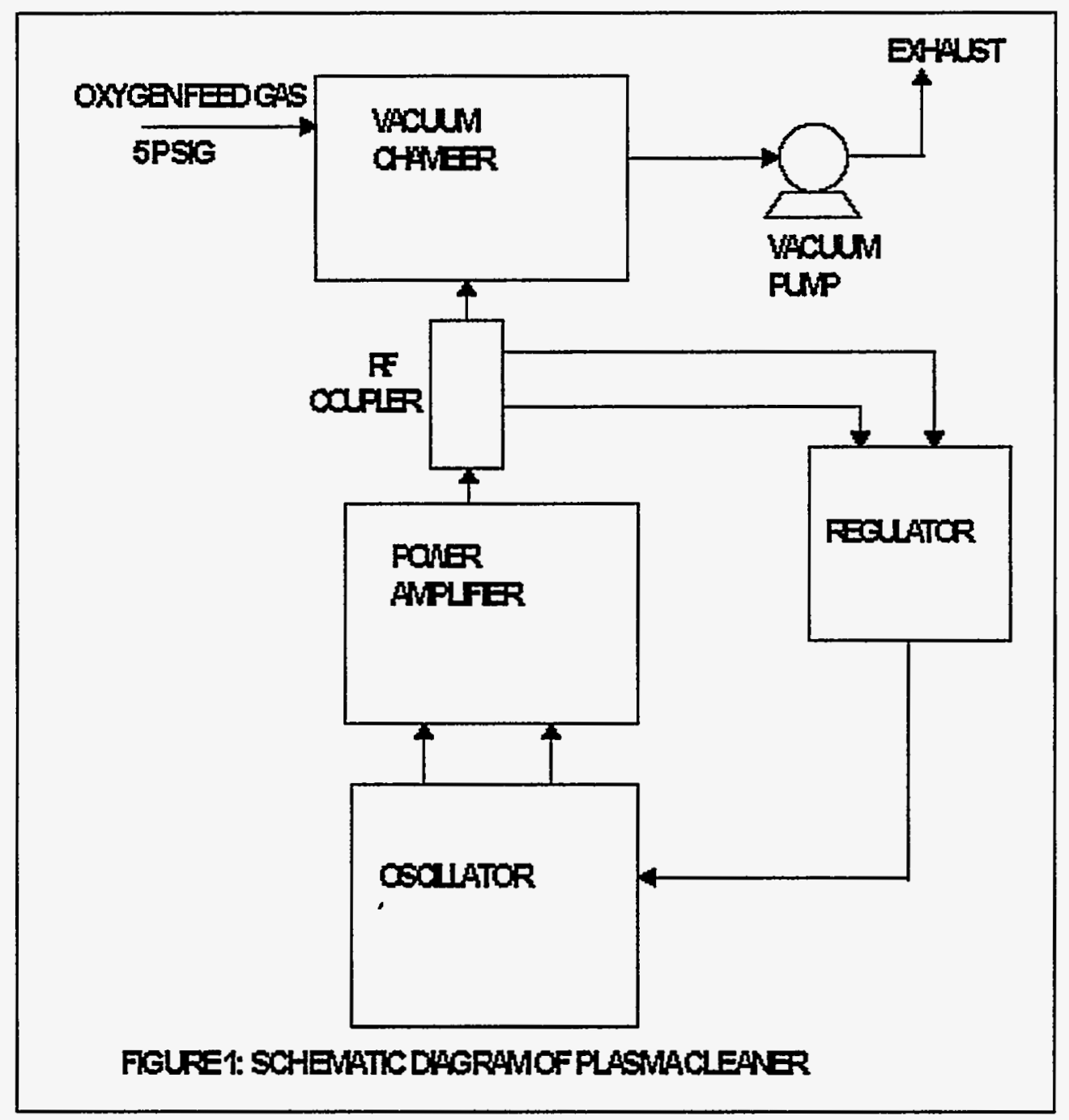


The oscillator, power amplifier, coupler, and regulator constitute a feedback control system regulating the output power at a level determined by the if level control located on the generator. The oscillator generates a $13.56 \mathrm{MHz}$ sine wave which is amplified by the power amplifier. The amplitude of the oscillator's output is controlled by the regulator. The coupler detects the power supplied by the power amplifier and outputs a dc signal proportional to the power. This dc signal is fed to the regulator where it is compared with the setting of the remote power level setting. The (rf) power range adjusts from 0 to 400 watts. The power supply is capacitively coupled to the reaction chamber via external electrodes. The if generator is designed to engage when the pressure is between 0.1 torr and 2.0 torr. When operated in automatic mode, the longest cleaning time allowed is 100 minutes. The chamber of the barrel reactor was made of quartz. This material is chosen because of its purity and noninterference with the plasma. The chamber size was 10 inches in diameter and 20 inches deep. A ten-inchwide quartz grid $\left(0.5^{\prime \prime}\right.$ squares) shelf running the length of the chamber held the hybrids that were to be cleaned. The chamber is evacuated by a Leybold-Heraeus dual-stage rotary vane vacuum pump. It maintained the chamber pressure for a given gas flow rate. The chamber pressure varied with flow rate as shown in Table 2.

Table 2. Gas Flow Rate to Chamber Pressure Correlation

\begin{tabular}{|c|c|}
\hline Chamber Pressure (Torr) & Gas Flow Rate (cc/min) \\
\hline 0.3 & 25 \\
\hline 0.7 & 300 \\
\hline 1.1 & 725 \\
\hline
\end{tabular}

\section{Experimental Design}

\section{Factorial Design of Experiment}

The overall strategy of experimental design, once the variables and their ranges of interest are determined, is to discover as much as possible about the entire system. Factorial designs meet this strategy because each experimental run yields information about every variable and the interactions among them. This is accomplished by making experimental runs at all combinations of the variables. The results can then be used to empirically model the process.

The name "factorial" refers to the method of calculating the number of experiments required to model the process. If the number of factors is $n$, and for each factor there are $k$ levels or settings of interest, then the number of runs required for one experiment is $k^{n}$. Therefore, a two-level, three-factor experiment would require $2^{3}$ or eight runs. Figure 2 gives a visual representation of a two-level, three-variable factorial experiment. Data are collected at each node and the "volume" of the cube is empirically modeled using the combination of results obtained from the eight experiments. It should be noted that only a linear model in each factor can be made with a two-level experiment. In order to measure second order effects which estimate curvature of the response surface and variable interaction, a third level must be added. The addition of the third level to a three-factor experiment increases the number of runs to 27 . Figure 3 is a representation of a three-variable, three-level full factorial experiment. 


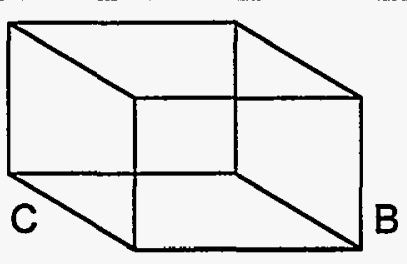

A
$A=$ variable 1

$B=$ variable 2

$\mathrm{C}=$ variable 3

Figure 2. Visual Representation of Two-Level, Three-Factor Factorial Experiment
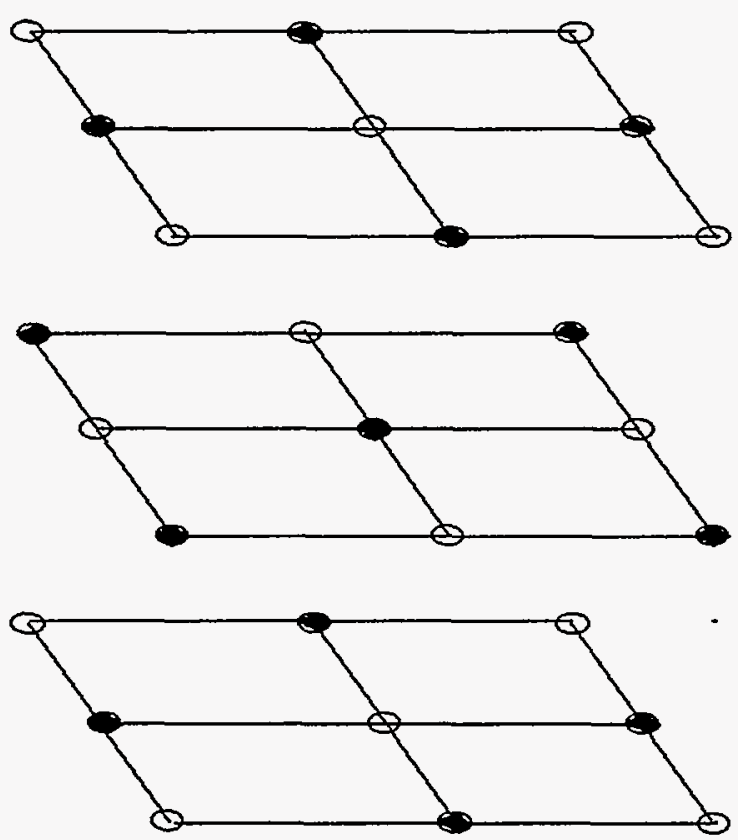

Figure 3. Full Factorial Design With Box-Behnken Design in Black

It can be seen that as the number of variables or levels increases, the number of experiments per design increases to a point where it may not be economical to run a full factorial experimental design. If the number of variables increases to five or six, screening tests should be run to reduce the number of experiments and determine which factors and interactions are the most significant. This can be accomplished by several methods. One method used in this study was to review literature examining similar processes. From their studies, the significant variables can often be identified, and extraneous variables can be eliminated without running an experiment. If screening experiments are necessary, they are still based on the principles of a 
full-factorial design, but a smaller number of runs for a given number of factors are made. The price paid for utilizing a reduced number of runs is that test results no longer contain information about single main or interaction effects. Instead, these data points represent the main effects plus some interaction effects. However, according to Box, Hunter, and Hunter (1978), tertiary and higher interactions are typically insignificant to the overall response surface. ${ }^{24}$ Therefore, the screening runs can be designed to allow the tertiary and above interactions to confound the primary and secondary interactions without great consequence to the experiment.

\section{Method of Designing Box-Behnken Experiment}

Another technique used to reduce the number of experimental runs is to select test runs at the midpoint of each edge of the cube and in the center. This method, known as a Box-Behnken design, reduces a three-level, three-variable factorial design from 27 to 15 runs. All 12 of the edge points lie on a single "sphere-like shape" about the experimental region. The remaining three runs are at the center of the volume. The test points shaded black in Figure 3 represent the experimental points in a Box-Behnken design. Choosing the test runs at these locations allows the estimation of the curvature of the response surface and first order interactions.

Once the variables have been selected, the steps required for a Box-Behnken experiment are as follows:

1. The values of the outer limits of the range of each variable and the midpoint of the ranges should be determined. These limits represent the two levels for each variable. The addition of the midpoint measurements permits estimation of the curvature of the response surface. The upper level will be represented with a "+," the lower level will be represented with a "-," and the midpoint represented with a "0." The levels should be sufficiently separated to clearly distinguish the response surface variations and minimize the effects of experimental error. In other words, widely spaced values for each independent variable improve the chances of identifying significant effects by experimentation or show that no effect other than experimental error occurs for that process.

2. The responses being measured on each run should be continuous functions and contain uniform independent error. Uniform independent errors are those that will have the same magnitude at each experimental measurement point.

3. A design table is then developed which specifies the level for each variable for each run. Table 3 is a representation of a two-level, three-factor experiment including a midpoint for curvature analysis (Box-Behnken design). The order of running the trials should be randomized in order to reduce bias error.

4. The number of repetitions necessary depends on the predetermined statistical significance required for the process. Replication of the system is required to estimate the variance of the random error and to satisfy the confidence level requirements when deciding the significance of a factor. 
Table 3. Box-Behnken Design and Random Order of Experiment

\begin{tabular}{|c|c|c|c|c|}
\hline \multirow{2}{*}{ RUN } & \multicolumn{3}{|c|}{ FACTOR } & \multicolumn{2}{l|}{$\begin{array}{l}\text { RANDOM } \\
\text { ORDER OF } \\
\text { EXPERIMENT }\end{array}$} \\
\cline { 2 - 5 } & $X_{1}$ & $X_{2}$ & $X_{3}$ & 13 \\
\hline 1 & 0 & + & + & 3 \\
\hline 2 & 0 & + & + & 11 \\
\hline 3 & 0 & - & - & 5 \\
\hline 4 & 0 & - & 0 & 8 \\
\hline 5 & + & + & 0 & 4 \\
\hline 6 & - & + & 0 & 12 \\
\hline 7 & + & - & 0 & 15 \\
\hline 8 & - & - & + & 10 \\
\hline 9 & + & 0 & + & 2 \\
\hline 10 & - & 0 & - & 7 \\
\hline 11 & + & 0 & - & 9 \\
\hline 12 & - & 0 & 0 & 6 \\
\hline 13 & 0 & 0 & 0 & 14 \\
\hline 14 & 0 & 0 & 0 & 1 \\
\hline 15 & 0 & 0 & & \\
\hline
\end{tabular}

\section{Mathematical Correlation Equation Development}

Following a carefully designed experiment, an empirical equation that represents the process can be established. The Box-Behnken design has three levels for each variable and replicates the center point three times, so a second order or quadratic equation can be established. The replication of the center point is necessary to estimate the pure experimental error (random error). The equation is said to be linear when the coefficients $(\beta)$ are linear. The order of the equation is determined by the number of levels of data points collected for each variable and is equal to the highest power of a predictor variable. Using the data collected from the BoxBehnken designed experiment, a second order polynomial equation can be developed as shown in (7).

$$
Y_{\text {mod }}=\beta_{0}+\beta_{1} X_{1}+\beta_{2} X_{2}+\beta_{3} X_{3}+\beta_{4} X_{1}^{2}+\beta_{5} X_{2}^{2}+\beta_{6} X_{3}^{2}+\beta_{7} X_{1} X_{2}+\beta_{8} X_{1} X_{3}+\beta_{9} X_{2} X_{3}+\varepsilon
$$

Establishing a quadratic equation to mathematically describe the process requires a method to estimate the equation coefficients. The method of least squares, also known as regression analysis, is commonly used to determine the coefficients. The method of least squares finds the "best-fitting correlation" by minimizing the sum of squared differences between the data collected in the experiments and the value estimated by the model. The quantity being minimized is shown in equation (8)

$$
S_{R}=\Sigma\left(Y_{\text {act }}-Y_{\text {mod }}\right)^{2}
$$


The quantity $S_{R}$ is known as the residual sum of squares and is the sum of squared discrepancies between the observed values, $Y_{\text {act, }}$ and the values given by the model, $Y_{\text {mod. }}$ Substituting the right hand side of equation (7) for $Y_{\text {mod }}$ into equation (8), it is seen that $S_{R}$ is a function of the coefficients $\beta_{i}$. To obtain the best fitting model, we must find the values of $\beta_{\mathrm{i}}$ that minimizes equation (9).

$$
S_{R}=\Sigma\left(Y_{\text {act }}\left\{\beta_{0}+\beta_{1} x_{1}+\beta_{2} x_{2}+\beta_{3} x_{3}+\beta_{4} x_{1}^{2}+\beta_{5} x_{2}{ }^{2}+\beta_{6} x_{3}{ }^{2}+\beta_{7} x_{1} x_{2}+\beta_{8} x_{1} x_{3}+\beta_{9} x_{2} x_{3}\right\}\right)^{2}
$$

\section{Calculating $\beta_{\mathrm{I}}$}

To find values of $\beta_{i}$ that minimize equation (9), the equation is differentiated with respects to $\beta_{i}$.

$$
\begin{gathered}
\partial S / \partial \beta_{0}=-2 \Sigma\left(Y_{\text {act }}-\beta_{0}-\beta_{1} x_{1}-\ldots-\beta_{9} x_{2} x_{3}\right) \\
\partial S / \partial \beta_{1}=-2 \Sigma\left(Y_{\text {act }}-\beta_{0}-\beta_{1} x_{1}-\ldots-\beta_{9} x_{2} x_{3}\right) x_{1} \\
\cdot \\
\cdot \\
\partial S / \partial \beta_{9}=-2 \Sigma\left(Y_{\text {act }}-\beta_{0}-\beta_{1} x_{1}-\ldots-\beta_{9} x_{2} x_{3}\right) x_{2} x_{3}
\end{gathered}
$$

Setting each of these partial derivatives to zero gives a set of ten normal equations that, when solved simultaneously, yield the values of the elements of $\beta$ that will minimize equation (9).

The matrix version of the normal equations and solution for $\beta$, when there are $n$ experimental runs and $p$ factors in the modeling equation, is as follows:

$$
Y_{\text {mod }}=X \beta
$$

where $\mathrm{Y}_{\text {mod }}$ is the $n \times 1$ vector of expected values for the response, $\mathrm{X}$ is the $n \times p$ matrix of independent variables, and $\beta$ is the $p \times 1$ vector of parameters.

The normal equations written in vector form:

$$
\mathbf{X}^{\top}\left(\mathbf{Y}_{\text {act }}-\mathbf{Y}_{\text {mod }}\right)=0
$$

where $Y_{\text {mod }}$ is the value of the model and the $\left(^{\top}\right)$ means transpose of the matrix. Substituting $X \beta$ for $Y_{\text {mod }}$ the equation becomes

$$
X^{\top}\left(Y_{\text {act }}-X \beta\right)=0
$$

which can be solved for $\beta$ to give

$$
\beta=\left[X^{\top} X\right]^{-1} X^{\top} y
$$


Once the values of $\beta$ have been determined, they are inserted into equation (7) in order to form the correlation equation.

\section{Test of Factor Coefficients}

After the correlation equation has been identified and the data has been collected at each point of the Box-Behnken design, the determination of the significance of each factor is determined by a standard statistical F-test and P-value as outlined in Dunn and Clark (1987). ${ }^{25}$ The F-test is based on the variance of a particular factor (i.e., power, time, pressure) to the variance of the experimental error inherent in the system. The F-ratio is calculated by dividing the sum of the mean square value for the particular variable and the mean square value of the total error by the mean square value of the total error as shown in the following equation.

$$
\left(M S_{\text {var }}+M S_{\text {sys }}\right) / M S_{\text {sys }}
$$

The mean square value of the total error is a calculation of the experimental error.

Equation (15) would yield a value near 1.0 if the factor being tested had no effect on the outcome. From the F-ratio, the P-value can be calculated. The P-value is the area under the F-distribution that lays to the right of the F-ratio. It represents the probability that the given F-ratio occurred at random. The experimenter predetermines a level of significance (the typical standard used in industry is $P=0.05$ ), and any $P$-value equal to or below that level identifies the factors to use in the correlation equation. If a factor had a P-value of 0.05 or less, that means the corresponding F-ratio would occur only $5 \%$ of the time due to random error. In other words, we are $95 \%$ confident that the F-ratio occurred because of the influence of the variable on the objective function.

\section{Correlation Equation's Lack of Fit}

Finally, a test of the equation is made to determine if it is an accurate representation of the process. The residual sum of squares is the sum of pure experimental error $\left(S_{E}\right)$ and lack of fit error $\left(S_{L}\right)$ as shown in equation (16).

$$
S_{R}=S_{E}+S_{L}=S\left(Y_{\text {act }}-Y_{\text {mod }}\right)^{2}
$$

The lack of fit error refers to the portion of the residual sum of squares that occurs because the calculated equation does not fit the data. By subtracting the pure experimental error (found by the replication of an experimental point) from the overall residual sum of squares a value for the lack of fit is known. Calculating the F-Ratio and P-value for the lack of fit factor will measure the accuracy of the model. If the P-value is equal to or below the investigators predetermined level (typically 0.05 ), the lack of fit is significant and the equation is inadequate.

With the number of variables identified, the experimental design chosen, the collection of data points randomized, and a method for correlating the data established, the next step is to determine how to measure the data of interest. The testing method for data collection is key to characterizing the process. 


\section{Test Method Selection for Data Collection}

An important issue to address when selecting a testing method for the process response surface is to choose one that will have the resolution necessary to observe a variation in output over the range of variables being studied. The selected test method should yield continuous data and not attribute data. This project was concerned with the surface cleanliness of the package containing one or more dice. To determine the cleaning ability of oxygen plasma, Auger spectrophotometry was used to measure the residual contamination thickness on the surfaces after cleaning. Auger electron spectroscopy (AES) identifies the elemental composition of the outermost monolayers of the devices being tested. (See appendix $A$ for details.) The contamination on the surfaces is organic, so the thickness of carbon is measured during analysis. The Auger results can be plotted as a function of the main operating parameters of the cleaning process. The selection of parameters that correspond to a minimum carbon depth on the surfaces defines the desirable settings for the plasma cleaning process.

The other concern of this project was electrical damage to the devices caused by exposure to the plasma. The parameter of concern is the leakage current between the emitter, base and collector on transistors, and the reverse leakage current on diodes. These parameters are most likely to be affected by the plasma, because high energy electrons can penetrate the silicon oxide on the surface of the die and either knock lattice electrons loose or become lodged in the crystal. If electrons are knocked out, holes will appear in lattice and can migrate to electrically active regions of the device, causing leakage currents to increase. The Lorlin Impact IV tester, used for all production testing, was used to electrically test the devices before and after cleaning to measure the shift in electrical parameters. (See appendix B.)

\section{Experimental Procedure}

The actual procedure followed to collect the data for analysis was the following.

1. Sixty devices were assembled for the surface analysis portion of the Box-Behnken experimental design.

2. During one 24-hour period, two devices were loaded together into the vacuum chamber and cleaned at one of the settings as given in Table 3.

3. Immediately after cleaning the two samples were taken to the Auger equipment and loaded into the vacuum chamber for analysis.

4. The entire Box-Behnken experimental design was run twice, taking 30 days to collect 60 data points.

5. For the electrical test data, a sample of twenty devices (except for diodes cleaned at 200 watts for 15 minutes which had a sample of ten) were plasma-cleaned at each setting and tested on the Lorlin Impact IV tester. 
6. Analysis of the Box-Behnken experimental design led to a second experimental design to finalize the characterization of the plasma cleaning process.

7. The second experimental design (two by four full factorial) required an additional six data points to be collected. Two samples were again cleaned simultaneously and analyzed; however, these points were not repeated.

\section{Data Analysis}

Analysis of the Auger data and electrical test data was done using JMP, a windows-based software program developed by SAS Institute Inc., Cary, NC. SAS (the name of the mainframe software package) has been the plant standard at AlliedSignal FM\&T and is recognized by industry as the leading statistical analysis software package. It is recommended by Dunn and Clark (1987), because of its extensive analysis of variance and regression analysis and its double precision arithmetic. ${ }^{25}$ Although JMP is not as powerful as SAS, portions of it were adapted from the routines in the SAS System, particularly for linear algebra and probability calculations.

\section{Results}

An experimental plan, based on a partial factorial design known as a Box-Behnken design, was developed and executed. This design minimized the number of experimental runs required to initially study the process and verify the dependence of the contamination thickness on each of the operating variables of the plasma cleaner. From these results a second study was run to finalize the characterization and correlate the operating conditions to the thickness of contamination remaining on the die surfaces. The results are broken into three sections.

1. Results of the initial experimental design

2. Extension and finalized process characterization

3. Evaluating the electrical test data

\section{Results of the Initial Experimental Design}

Following the schedule of experiments outlined in Table 3 and the outlined procedure, the depth of contamination on the die bond pads was determined by Auger spectrophotometry. Table 4 lists the average contamination thickness remaining on the die bond pads after oxygen plasma cleaning at the specified parameters. The average contamination was calculated from four devices cleaned at each of the settings. Two devices were cleaned in one experimental run, and the entire experimental design was duplicated once. 
Table 4. Results of Auger Analysis of Aluminum Bond Pads After Oxygen Plasma Cleaning

\begin{tabular}{|c|c|c|c|}
\hline $\begin{array}{c}\text { Power } \\
\text { (Watts) }\end{array}$ & $\begin{array}{c}\text { Pressure } \\
\text { (Torr) }\end{array}$ & $\begin{array}{c}\text { Time } \\
\text { (Minutes) }\end{array}$ & $\begin{array}{c}\text { Avg. Contamination } \\
\text { Depth (Angstroms) }\end{array}$ \\
\hline 50 & 0.7 & 5 & 240 \\
\hline 50 & 0.3 & 10 & 200 \\
\hline 50 & 1.1 & 10 & 200 \\
\hline 50 & 0.7 & 15 & 180 \\
\hline 100 & 1.1 & 5 & 150 \\
\hline 100 & 0.3 & 5 & 210 \\
\hline 100 & 0.7 & 10 & 75 \\
\hline 100 & 0.7 & 10 & 100 \\
\hline 100 & 0.7 & 10 & 100 \\
\hline 100 & 1.1 & 15 & 85 \\
\hline 100 & 0.3 & 15 & 130 \\
\hline 150 & 0.7 & 5 & 50 \\
\hline 150 & 1.1 & 10 & 25 \\
\hline 150 & 0.3 & 10 & 25 \\
\hline 150 & 0.7 & 15 & 10 \\
\hline
\end{tabular}

The data gathered in these experimental runs were statistically analyzed using the F-test to determine the significance of the three independent variables, as well as their interaction. Table 5 gives the P-values associated with each of the three variables as well as the interactions among them.

Table 5. Analysis of Variance for Depth of Contamination

\begin{tabular}{|c|c|c|c|c|c|}
\hline Source & Sum of Squares & $\begin{array}{c}\text { Degrees of } \\
\text { Freedom }\end{array}$ & $\begin{array}{c}\text { Mean } \\
\text { Square }\end{array}$ & F-Ratio & P-value \\
\hline $\mathrm{X}_{1}$ :power & 63012.5 & 1 & 63012.5 & & 0.0001 \\
\hline $\mathrm{X}_{2}:$ time & 7503.13 & 1 & 7503.13 & & 0.008 \\
\hline $\mathrm{X}_{3}:$ pressure & 1378.12 & 1 & 1378.12 & & 0.127 \\
\hline $\mathrm{X}_{1}{ }^{2}$ & 7.85 & 1 & 7.85 & & 0.897 \\
\hline $\mathrm{X}_{1} \mathrm{X}_{2}$ & 100 & 1 & 100 & & 0.6482 \\
\hline $\mathrm{X}_{1} \mathrm{X}_{3}$ & 0 & 1 & 0 & & 1 \\
\hline $\mathrm{X}_{2}{ }^{2}$ & 3277.08 & 1 & 3277.08 & & 0.0371 \\
\hline $\mathrm{X}_{2} \mathrm{X}_{3}$ & 56.25 & 1 & 56.25 & & 0.7307 \\
\hline $\mathrm{X}_{3}{ }^{2}$ & 1834.78 & 1 & 1834.78 & & 0.0886 \\
\hline total error & 2060.42 & 5 & 412.083 & $\mathrm{NA}$ & $\mathrm{NA}$ \\
\hline
\end{tabular}


Based upon the P-values, it can be seen from Table 5 that the two factors that had the largest impact on cleaning the die surface were the time and power setting. These were expected results, as increasing time allows the cleaning reaction to continue and increasing the power of the electric field increases the energy absorbed by the plasma gas. This increases the concentration of oxygen radicals that react with the organics on the surface and increases the velocity of the electron cloud. A measurement reflecting the increased energy of the plasma was the change in temperature measured through the course of the cleaning process. The change in temperature when processing at 150 watts was $52^{\circ} \mathrm{C}$ to $72{ }^{\circ} \mathrm{C}$, depending on the time, versus $11^{\circ} \mathrm{C}$ to $27^{\circ} \mathrm{C}$ for processing at 50 watts.

The $P$-value for the power squared factor $\left(X_{1}^{2}\right)$, the power-time interaction factor $\left(X_{1} X_{2}\right)$, the power-pressure interaction factor $\left(X_{1} X_{3}\right)$, and the time-pressure interaction factor $\left(X_{2} X_{3}\right)$ indicated that they were not statistically significant. In these cases 65 to $100 \%$ of the time the values found for these factors would have occurred due to random fluctuation of the process. Pressure was also shown not to be a significant factor in the cleaning process within the range studied. However, its significance can change when the other four insignificant factors are eliminated. Table 6 shows the results of the analysis of variance when these terms were removed.

Table 6. Analysis of Variance After Removal of Statistically Insignificant Terms

\begin{tabular}{|c|c|c|c|c|c|}
\hline Source & $\begin{array}{c}\text { Sum of } \\
\text { Squares }\end{array}$ & $\begin{array}{c}\text { Degrees of } \\
\text { Freedom }\end{array}$ & $\begin{array}{c}\text { Mean } \\
\text { Square }\end{array}$ & F-Ratio & P-Value \\
\hline $\mathrm{X}_{1}:$ power & 63012.5 & 1 & 63012.5 & 302.46 & 0.0033 \\
\hline $\mathrm{X}_{2}:$ time & 7503.13 & 1 & 7503.13 & 36.01 & 0.0267 \\
\hline $\mathrm{X}_{3}:$ pressure & 1378.12 & 1 & 1378.12 & 6.61 & 0.1237 \\
\hline $\mathrm{X}_{2}{ }^{2}$ & 3321.46 & 1 & 3321.46 & 15.94 & 0.0574 \\
\hline $\mathrm{X}_{3}{ }^{2}$ & 1864.32 & 1 & 1864.32 & 8.95 & 0.0959 \\
\hline total error & 2224.52 & 9 & 247.169 & na & na \\
\hline
\end{tabular}

After removing the power squared term, the power-time interaction term, the power-pressure interaction term, and the time-pressure interaction term, no change in the significance of pressure was seen. Therefore, pressure was clearly not an influencing factor of this system in the range studied.

The results of the initial study verified the dependence of the contamination thickness on power and time and proved that pressure was not a significant variable within the range studied. Table 4 indicated that nearly all contamination was removed from the semiconductor's surface when it was cleaned at 150 watts of power for 15 minutes. The results of the electrical testing, which are discussed in detail in a later section, for parts cleaned 15 minutes at 150 watts were well below the specification limits allowed, suggesting that cleaning at higher powers and longer times may be possible without causing unacceptable electrical damage. From these results it was determined that a second experimental design, which increased the range of study and reduced the number of variables to two, time and power, be developed. 


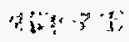

$$
\begin{aligned}
& \text { * He... I" }
\end{aligned}
$$

\section{Finalized Process Characterization}

A second experimental design, based on the observations of the results of the initial experimental design, was developed and executed. Three changes were made to the original experiment: pressure was held constant at 0.7 torr, the range for power was increased by 50 watts and spanned from 50 to 200 watts, and the time range was expanded up to 25 minutes. The power and time were increased to attempt to remove all measurable contamination from the device surface. A four-level, full-factorial experimental design with two variables, time and power, was chosen to characterize the oxygen plasma process. Sixteen experimental runs were required for a two by four, full-factorial experiment. By taking advantage of the data gathered in the first experimental design, only seven new data points remained to be collected. Auger spectroscopy was again used to determine the thickness of contamination on the device surface after plasma treatment. Table 7 shows the average contamination thickness on the die bond pads after oxygen plasma cleaning for the new range of time and power studied.

Table 7. Results of Auger Analysis of Aluminum Bond Pads After Oxygen Plasma Cleaning

\begin{tabular}{|c|c|c|c|}
\hline $\begin{array}{c}\text { Power } \\
\text { (Watts) }\end{array}$ & $\begin{array}{c}\text { Time } \\
\text { (Minutes) }\end{array}$ & Source & $\begin{array}{c}\text { Average Contamination } \\
\text { Depth (Angstroms) }\end{array}$ \\
\hline 50 & 5 & first experimental design & 240 \\
\hline 50 & 10 & first experimental design & 200 \\
\hline 50 & 15 & first experimental design & 180 \\
\hline 50 & 25 & new data point & 120 \\
\hline 100 & 5 & first experimental design & 150 \\
\hline 100 & 10 & first experimental design & 100 \\
\hline 100 & 15 & first experimental design & 75 \\
\hline 100 & 25 & new data point & 30 \\
\hline 150 & 5 & first experimental design & 50 \\
\hline 150 & 10 & first experimental design & 20 \\
\hline 150 & 15 & first experimental design & 10 \\
\hline 150 & 25 & new data point & 0 \\
\hline 200 & 5 & new data point & 0 \\
\hline 200 & 10 & new data point & 0 \\
\hline 200 & 15 & new data point & 0 \\
\hline 200 & 25 & new data point & 0 \\
\hline
\end{tabular}


The result of increasing the power to 200 watts was total elimination of the surface contamination. Auger analysis found no measurable carbon on the aluminum bond pads when the parts were cleaned for as little as 5 minutes at 200 watts of power. A 3D plot of the estimated response surface was generated from the data in Table 7 and is shown in Figure 4. A contour plot of the data can be seen in Figure 5. The data gathered in these experimental runs were statistically analyzed to measure the significance of each variable and their interactions. The significance of each coefficient was determined by the calculated F-Ratio and $\mathrm{P}$-value. Table 8 give the results of the statistical tests for each term and their interactions. From the P-value listed in the analysis of variance it can be seen that the time squared term $\left(X_{2}^{2}\right)$ was not statistically significant.

Table 8. Analysis of Variance for the Second Experimental Design

\begin{tabular}{|l|l|l|l|l|l|}
\hline Source & $\begin{array}{l}\text { Sum of } \\
\text { Squares }\end{array}$ & $\begin{array}{l}\text { Degrees of } \\
\text { Freedom }\end{array}$ & $\begin{array}{l}\text { Mean } \\
\text { Square }\end{array}$ & F-Ratio & P-Value \\
\hline$X_{1}:$ power & 69269.8 & 1 & 69269.8 & 344.96 & 0 \\
\hline$X_{2}:$ time & 9500.23 & 1 & 9500.23 & 47.31 & 0 \\
\hline$X_{1}{ }^{2}$ & 5665.9 & 1 & 5665.9 & 28.22 & 0.0002 \\
\hline$X_{2}{ }^{2}$ & 2.4251 & 1 & 2.4251 & 0.01 & 0.9155 \\
\hline$X_{1} X_{2}$ & 4699.86 & 1 & 4699.86 & 23.41 & 0.0004 \\
\hline Total error & 2409.65 & 12 & 200.804 & na & na \\
\hline
\end{tabular}

A correlation equation to relate the operating parameters to the thickness of contamination can be developed from the statistical analysis of the data collected in the experimental design. For this study the process response is the remaining thickness of contamination on the die surface after cleaning. For the two-variable, four-level, full factorial experiment the correlation equation is given by equation (17).

$$
Y_{\text {mod }}=\beta_{0}+\beta_{1} X_{1}+\beta_{2} X_{2}+\beta_{3} X_{1}^{2}+\beta_{4} X_{2}^{2}+\beta_{5} X_{1} X_{2}
$$

The P-value of the $X_{2}^{2}$ term was greater than 0.05 , implying that this term was not statistically significant and $\beta_{4}$ is set to zero. The remaining variables and their interactions determine the empirical equation (or objective function) which correlates the process response to the operating parameters. The correlation equation for the oxygen plasma cleaning process relating contamination thickness to the operating parameters reduces to equation (18).

$$
Y_{\bmod }=435.083-3.60081 X_{1}-8.45127 X_{2}+0.0071838 X_{1}^{2}+0.0413479 X_{1} X_{2}
$$

where $Y_{\text {mod }}$ is the calculated thickness of contamination remaining, $X_{1}$ is the power setting in watts, and $X_{2}$ is the cleaning time in minutes. 


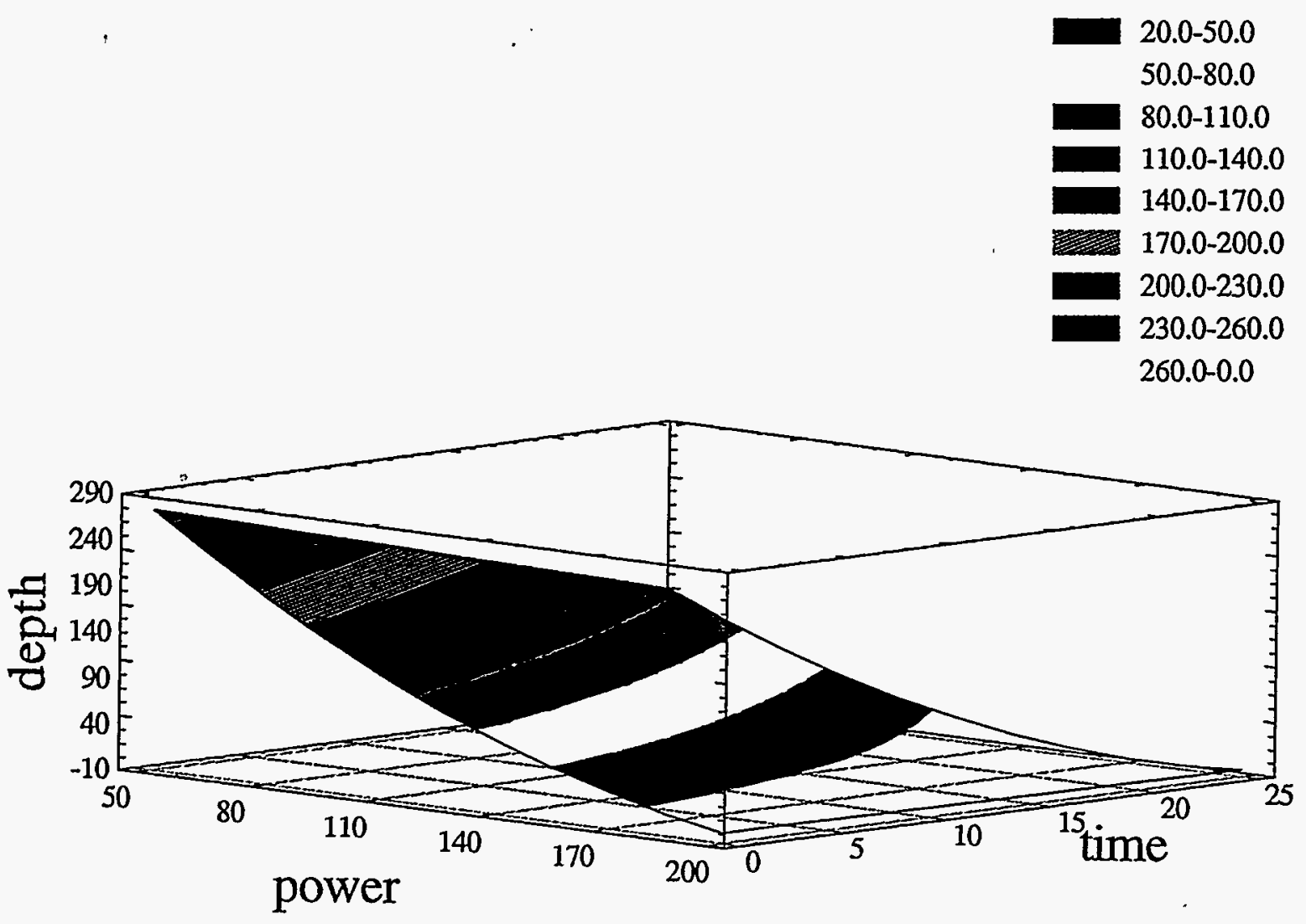

Figure 4. Estimated Response Surface for Oxygen Plasma-Cleaned Die Bond Pads 
20.0-50.0

50.0-80.0

80.0-110.0

$110.0-140.0$

$140.0-170.0$

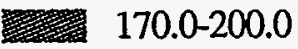

200.0-230.0

$230.0-260.0$

260.0-0.0

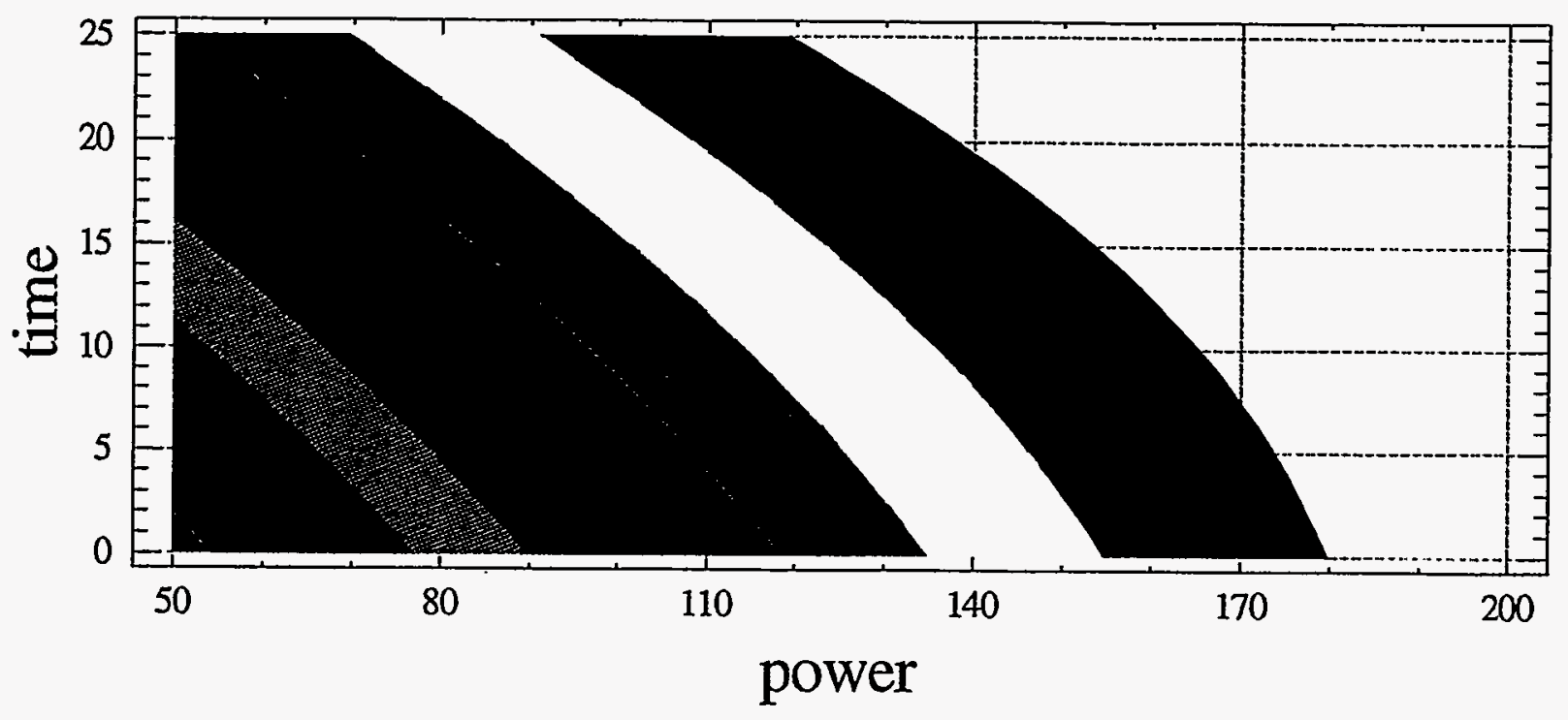

Figure 5. Contours of the Estimated Oxygen Plasma Cleaning Response Surface 
As a final check of the correlation equation, the "lack-of-fit" calculation was made. The lack-offit error refers to the portion of the residual sum of squares that occurs because the calculated equation does not fit the collected data. An F-Ratio and P-value can be calculated for the "lackof-fit" the same way it was done for each coefficient. The "lack-of-fit" P-value was calculated to be 0.2387 , meaning it is insignificant, and the equation can be considered to be a good fit of the experimental data. This is verified in Table 9, which gives the measured and calculated values of the data points for each set of cleaning parameters.

Table 9. Values of Actual Contamination Thickness Measurements and Calculated Contamination Thickness for the Given Cleaning Parameters

\begin{tabular}{|c|c|c|c|}
\hline $\begin{array}{c}\text { Power } \\
\text { (Watts) }\end{array}$ & $\begin{array}{c}\text { Time } \\
\text { (Minutes) }\end{array}$ & $\begin{array}{c}\text { Actual Thickness } \\
\text { (Angstroms) }\end{array}$ & $\begin{array}{c}\text { Calculated } \\
\text { Thickness } \\
\text { (Angstroms) }\end{array}$ \\
\hline 50 & 5 & 240 & 241.083 \\
\hline 50 & 10 & 200 & 209.164 \\
\hline 50 & 15 & 180 & 177.244 \\
\hline 50 & 25 & 120 & 113.406 \\
\hline 100 & 5 & 150 & 125.258 \\
\hline 100 & 10 & 100 & 103.676 \\
\hline 100 & 15 & 110 & 82.0935 \\
\hline 100 & 25 & 25 & 38.9288 \\
\hline 150 & 5 & 45 & 45.3524 \\
\hline 150 & 10 & 25 & 34.107 \\
\hline 150 & 15 & 30 & 22.8616 \\
\hline 150 & 25 & 0 & 0.3708 \\
\hline 200 & 5 & 0 & 1.365 \\
\hline 200 & 10 & 0 & 0.457 \\
\hline 200 & 15 & 0 & -0.451 \\
\hline 200 & 25 & 0 & -2.268 \\
\hline & & & \\
\hline
\end{tabular}

The close approximation of the calculated thickness to the measured thickness indicates the correlation equation is an adequate representation of the oxygen plasma cleaning process. Therefore, the correlation equation for the plasma cleaning process between 50 and 200 watts is given by equation (18) and is represented in Figures 4 and 5.

\section{Electrical Test Results}

The final phase of the investigation was to determine if a change in the electrical parameters of the devices due to plasma cleaning would limit the power setting for the cleaning process.

From the Auger data, it was clear that 200 watts would totally remove all measurable contamination from the die surface and would be the preferred setting. However, it was assumed the 200 watt setting would increase the leakage current of the devices to the point of failing the specification limits. To evaluate changes in the electrical parameters, samples of 
production parts containing six bipolar transistors; both PNP and NPN types, and two bipolar diodes were solder attached to the package, cleaned by the old method of vapor degreasing in trichlorotrifluoroethane, aluminum wire bonded, electrically tested, plasma cleaned and retested. Testing of the diodes included reverse (leakage) current and forward voltage. Transistors were tested for leakage current between the collector and base, the collector and emitter, and the base and emitter, as well as the voltage between collector and emitter, the voltage between base and emitter, and last, the gain. The collector, base, and emitter are the electrically active areas of the devices.

Table 10 shows the average change in the leakage current for the three devices for each cleaning power and the associated P-value calculated from an F-test.

Table 10. Average Increase in Leakage Currents for Bipolar Diodes and Transistors When Exposed to Oxygen Plasma

\begin{tabular}{|c|c|c|c|}
\hline $\begin{array}{c}\text { Power Setting/ } \\
\text { Time }\end{array}$ & $\begin{array}{c}\text { Diode Leakage } \\
\text { Current }\end{array}$ & $\begin{array}{c}\text { PNP Transistor } \\
\text { Leakage Current } \\
\text { (Collector/Base) }\end{array}$ & $\begin{array}{c}\text { NPN Transistor } \\
\text { Leakage Current } \\
\text { (Collector/Base) }\end{array}$ \\
\hline 100 watts/15 min & 6.57 & 2.63 & 2.89 \\
\hline 150 watts/ 15 min & 5.46 & 1.31 & 1.39 \\
\hline 200 watts/15 min & 7.48 & 2.13 & 1.81 \\
\hline P-value & 0.101 & 0.184 & 0.205 \\
\hline
\end{tabular}

Since more than two sets of data were being compared, an F-test was performed among each power setting to determine if there was any statistically significant difference in the shift among the groups. The F-test established that there was no significant difference among the increases in leakage current for the three power settings. This was an unexpected result given the information published by Harman (1991), Buck (1988), and Frieser (1987). ${ }^{20,19,21}$ Based upon the theory, increasing the power for the plasma increases the energy of the electrons and molecules. Increasing the power raises the potential to either knock more electrons from the silicon dioxide, creating holes, or implanting additional electrons in the top layer. The damage could then migrate to the active areas of the device and increase the leakage current. The expected result of the leakage current rising proportionally with the power did not occur. Instead, the increase was the same for all power settings, and all electrical test data stayed well below the limit values. Table 11 shows the specification limits for leakage current and the maximum value occurring for each cleaning power. 
Table 11. Specification Limits for Leakage Currents and Maximum Value Occurring at Each Power Setting

\begin{tabular}{|l|l|l|l|}
\hline Power Setting & $\begin{array}{l}\text { Diode Leakage } \\
\text { Current }\end{array}$ & $\begin{array}{l}\text { PNP } \\
\text { Collector/Base }\end{array}$ & $\begin{array}{l}\text { NPN } \\
\text { Collector/Base }\end{array}$ \\
\hline spec. limit & $75 \mathrm{nA}$ & $10 \mathrm{nA}$ & $10 \mathrm{nA}$ \\
\hline $100 \mathrm{~W}$ & 12.78 & 7.03 & 6.73 \\
\hline $150 \mathrm{~W}$ & 8.96 & 4.15 & 5.52 \\
\hline $200 \mathrm{~W}$ & 18.32 & 5.49 & 4.35 \\
\hline
\end{tabular}

Since the specification limits were not being threatened by any of the power settings, the change in the electrical characteristics will not constrain this process.

\section{Accomplishments}

\section{Conclusions}

The initial results from the Box-Behnken study showed that the power setting and the cleaning time of the plasma process were the most significant factors for removing organic contamination. Changes in pressure did not significantly affect the removal of contamination from the die surface. The contamination thickness ranged from a high of $240 \AA$ when cleaned at 50 watts for five minutes at a pressure of 0.7 torr to a low of $0 \AA$ after cleaning at 200 watts for 5 minutes at 0.7 torr.

A correlation between the process parameters and the remaining contamination thickness was established from the results of the second factorial experimental study. The correlation equation given in (19) is for the range of power between 50 and 200 watts and cleaning times of 5 to 25 minutes.

$$
Y_{\text {mod }}=435.083-3.60081 X_{1}-8.45127 X_{2}+0.0071838 X_{1}^{2}+0.0413479 X_{1} X_{2}
$$

At the beginning of this project it was believed that a change in the electrical parameters of the devices would establish the upper bound on the power and time allowed to clean the semiconductor devices. The purpose of the project was to map the contamination thickness as a function of power, time, and pressure with the upper constraint set by the change in leakage current of the semiconductor devices. Then the results of the plasma cleaning process would be compared to the results of the current CFC vapor degreasing process in order to validate the decision to replace the CFC degreasing process. It was found that the change in the leakage current stayed well below the specification limits through the entire range of power and time studied. The increase in leakage current of bipolar transistors and diodes when exposed to oxygen plasma was measurable. However, the change was associated with the fact of plasma 
exposure, not with the extent of the exposure. Contrary to the theoretical expectation that plasma exposure would alter the electrical properties proportionally with the power and time, it was concluded the relationship between electrical performance and extent of plasma exposure was unproven in the range studied.

Since the degradation of electrical performance proved not to be a constraint, the solution for AlliedSignal was to replace the solvent vapor degreasing process with the oxygen plasma process. The oxygen plasma cleaning parameters should be set at 0.7 torr, 150 to 200 watts, and 5 to 10 minutes for production operation. At these settings AlliedSignal gains a much improved cleaning method that yields cleaner surfaces at $1 / 6$ of the time of the CFC vapor degreasing process. The reduced processing time for cleaning becomes a cost savings to the division, because reducing the flow time of the product reduces the cost of manufacturing. Based on a production level of 300 pieces per month, an estimated annual cost savings of $\$ 2000$ could be achieved by changing the cleaning process.

\section{Recommendations}

Based on the results of this study, it was recommended that AlliedSignal immediately implement the use of oxygen plasma cleaning process to prepare semiconductor devices for wire bonding. This recommendation was accepted by AlliedSignal; the plasma cleaning process is now in use on test product. The current operating parameters are 150 watts for 10 minutes at a chamber pressure of 0.7 torr. At these settings, all measurable contamination will be removed from the device surface which will result in a reliable wire bond. The plasma process will improve manufacturing in two areas:

1. Reduce the manufacturing cost of the product by reducing the time required to clean devices by a factor of six.

2. Reduce the number and frequency of bond lifts that occur due to device contamination. 


\section{References}

'J. R. Hollahan and A. T. Bell, Techniques and Applications of Plasma Chemistry. New York: Wiley, 1974.

${ }^{2}$ H. Meyer, J. Phys. B 2, 393 (1969).

${ }^{3}$ Robert A. Alberty and Farrington Daniels, Physical Chemistry, SI Version, Fifth Ed., New York: Wiley, 1980.

"J. F. Graves, "Plasma Processing of Hybrids for Improved Bondability," The International J. Hybrid Microelectronics 6, 1983, pp 147-156.

${ }^{5}$ M. M. Khan, T. S. Tarter, and H. Fatemi, Aluminum Bond Pad Contamination by Thermal Outgassing of Organic Material from Silver-filled Epoxy Adhesives, IEEE Trans. on Components, Hybrids, and Manufacturing Tech. CHMT-10, 1987, pp 586-592.

${ }^{6}$ J. A. Weiner, G. V. Clatterbaugh, H. K. Charles, Jr., and B. M. Romenesko, Gold Ball Bond Shear Strength - Effects of Cleaning, Metallization, and Bonding Parameter, Proc. of the 33rd EEE Electronics Components Conference, Orlando, Florida, May 16-18, 1983, pp 208-220.

${ }^{7}$ L. M. Kenison, M. I. Gardner, and C. E. Doering, Oxygen Plasma Cleaning to Improve Hybrid Wire Bondability, Proc. of the 34th Electronics Components Conference, New Orleans, Louisiana, May 14-16, 1984, pp 233-238.

${ }^{8}$ Hui Kun Kim, "Plasma Cleaning of Spacecraft Hybrid Microcircuits and its Effect on Electronic Components," The International Journal for Hybrid Microelectronics, Volume 12, No. 3, September 1989, pp 144-148.

${ }^{9}$ David W. Daniel, Robin Bloom, and Jack E. Reece, Identifying an Etch Process Window Using Response Surface Methodology, Solid State Technology, September, 1988, pp 117-120.

${ }^{10}$ Mary W. Jenkins, Michael T. Mocella, Kenneth D. Allen, and Herbert H. Sawin, The Modeling of Plasma Etching Processes Using Response Surface Methodology, Solid State Technology, April, 1986, pp 175-181.

${ }^{11} \mathrm{M}$. lannuzzi, Development and Evaluation of a Preencapsulation Cleaning Process to Improve Reliability of HIC's with Aluminum Metallized Chips, IEEE Trans. on Components, Hybrids, and Manufacturing Technology CHMT-4, No. 4., December 1981, pp 429-438.

${ }^{12} \mathrm{~J}$. W. Mead, Cleaning Techniques for an $\mathrm{Al}_{2} \mathrm{O}_{3}$ Ceramic Wafers. Albuquerque: Sandia National Laboratories, Sandia Report SKND-78-0734, 1978. 
${ }^{13}$ H. B. Bonham and P. V. Plunkett, "Surface Contamination Removal from Solid State Devices by Dry Chemical Processing," published in Surface Contaminator, Genesis, Detection, and Control, K. L. Mittal, Editor. New York: Plenum Press, 1979; Vol. 1, 2.

${ }^{14} \mathrm{M}$. L. White, "Removal of Die Bond Epoxy Bleed Material by Oxygen Plasma," Proc. of the 32nd IEEE Electronics Components Conference, San Diego, California, May 10-12, 1982, pp. 262-265.

${ }^{15}$ S. L. Buckles, "The Use of Argon Plasma for Cleaning Hybrid Circuits Prior to Wire Bonding," Proc. of the International Symposium on Microelectronics (ISHM), Minneapolis, Minnesota, Sept. 28-30, 1987, pp 476-479.

${ }^{16} \mathrm{~J}$. K. Nesheim, "The Effects of Ionic and Organic Contamination on Wire Bond Reliability," Proc. of the 1984 International Symposium on Microelectronics, Dallas, Texas, Sept. 17-19, 1984, pp 70-78.

${ }^{17}$ Craig T. Fritsche, Organic Etch Capability of Various Gas Plasmas, (Topical Report). AlliedSignal Federal Manufacturing \& Technologies: KCP-613-4170, January 1990 (Available from NTIS).

${ }^{18}$ Craig T. Fritsche, Effect of Oxygen Plasma Cleaning on Thin Film Resistors, (Topical Report). AlliedSignal Federal Manufacturing \& Technologies: KCP-613-4507, December 1991 (Available from NTIS).

${ }^{19}$ Roy Buck, "Enhance Hybrid Reliability Through Plasma Cleaning," Hybrid Circuit Technology, December 1988, pp 13-16.

${ }^{20} \mathrm{G}$. G. Harman, Reliability and Yield Problems of Wire Bonding in Microelectronics, ISHM, 1991.

${ }^{21}$ R. G. Frieser, J. A. Bondur, and E. F. Gorey, "Oxygen Plasma Damage in Boron-Diffused Silicon," J. Electrochem Soc.: Solid-State Science and Technology, Vol. 134, February 1987, pp 419-424.

${ }^{22} \mathrm{~K}$. H. Ryden, and H. Norstrom, "Oxide Breakdown Due to Charge Accumulation During Plasma Etching," J. Electrochem. Soc.: Solid-State Science and Technology, Vol. 134, December 1987, pp 3113-3118.

${ }^{23}$ Peter H. Singer, Evaluating Plasma Damage in Thin Gate Oxides, Semiconductor International, August 1987, pp 36-38.

${ }^{24}$ G. E. P. Box, W. G. Hunter, and J. S. Hunter, Statistics for Experimenters. New York: Wiley, 1978.

${ }^{25}$ O. J. Dunn and V. A. Clark, Applied Statistics: Analysis of Variance and Regression, Second Edition. New York: Wiley, 1987. 
Appendix A

Auger Analysis Data 


\section{Auger Electron Spectroscopy}

\section{Introduction}

Auger electron spectroscopy (AES) is an analytical technique used to determine the elemental composition of the outermost monolayers of an electrically conductive solid. It relies on the detection of electrons, known as Auger electrons, emitted in the relaxation process of an ion. Auger electron emission is one of two possible relaxation mechanisms, the other being photon emission. All elements except hydrogen and helium can be detected by AES. Auger electron spectroscopy is accomplished by exciting the sample with a 3 to $20 \mathrm{keV}$ electron beam and measuring the kinetic energy of the Auger electrons which are emitted from the sample surface. Auger electrons are emitted with an energy between 40 and $2500 \mathrm{eV}$. Electrons in this energy regime have an escape depth of approximately 5 to 50 angstroms; therefore, the technique obtains information from the very surface (top few monolayers) of the sample. The technique , for chemical analysis of surfaces can be visualized as a two-step process. First, a high energy photon, generated by an electron beam, ejects an electron from a core orbital (1s) of an atom. Second, an electron falls from a higher energy orbital to fill the vacancy, thereby releasing sufficient energy to eject a second photoelectron from one of the higher energy orbitals.

The energy of the Auger electrons is measured with a cylindrical mirror analyzer (CMA) or with a spherical capacitor analyzer (SCA). Each element has a unique set of Auger peaks which are normally plotted on a derivative scale of relative counts versus kinetic energy. In certain instances, chemical state information for an element can be derived. While AES is normally used for analyzing conductive solids, it is also possible to analyze inorganic oxides.

An Auger electron spectroscopy system consists of an ultrahigh vacuum system; an electron gun for specimen excitation, and an energy analyzer for detection of Auger electron peaks in the total secondary electron energy distribution. The sensitivity of the Auger technique is determined by the transition probability of the Auger transitions involved, the incident beam current and energy, and by the collection efficiency of the analyzer.

Analysis of the devices' oxygen plasma cleaned in this experiment was conducted on the PHI 760xi Scanning Auger Nanoprobe (traditionally nicknamed the SAM, an acronym for Scanning Auger Microprobe), equipped with a NORAN Voyager X-Ray Detector system. The Auger system employs a Field Emission electron source to provide spectroscopy information at very low beam currents. The operator loads the part to be tested into the ultrahigh vacuum chamber and aligns it with the electron beam. Once the chamber reaches the required vacuum, the electron beam, which is aimed at the part of interest, is activated and the spectrum generated is compared to known standards. An elemental map of the top surface can then be constructed. The depth of the surface elements is determined by bombarding the surface with an argon gas and monitoring the time it takes to remove those elements. The surface is then remapped after a few seconds of sputtering. The sputter rate of the Auger analyzer used in this investigation was 40 angstroms per minute. 
The data collected on the Auger spectrometer was broken into two categories. The first category was the initial and final scans of the surfaces of the devices cleaned at the various cleaning parameters established in the experimental design. The purpose of the initial and final scans was to verify that carbon existed on the device surface prior to sputtering in the Auger analyzer and then verify that all the carbon was removed after sputtering was completed. The second category discusses the output spectrums during sputtering and the calculation method to determine the thickness of contamination on the die surface.

\section{Reading a Surface Analysis (Figures A-1 Through A-8)}

The output generated during an Auger spectral analysis is a plot of the energy distribution function, $N(E)$, versus the electron's kinetic energy over a range of 50 to $2000 \mathrm{eV}$. Figures A-1 through A-8 are examples of the surface survey spectrum. (All figures appear at the end of this appendix.) Figures $A-1$ through $A-7$ show the difference in carbon peak heights, as well as oxygen and aluminum peaks, after plasma cleaning under different conditions. Figure A-8 shows the surface condition after sputtering (no carbon present) and is representative of all spectrums collected after the sputtering process for each experimental point. Each element, except hydrogen and helium, emits an Auger electron which has a characteristic kinetic energy. The peaks in the output spectrum indicate the elements that are present. In this study, the elements of interest are aluminum and carbon. The carbon represents the organic residue on the die surface and the aluminum is the bond pad material. Oxygen will also have a strong signal since that is the gas used during plasma cleaning. Aluminum has two peaks, one at $68 \mathrm{eV}$ and the other at approximately $1400 \mathrm{eV}$. The low energy aluminum peak (68 eV) signifies the electrons are coming from the top $10 \AA$ of the surface. Contamination thickness greater than $10 \AA$ on the die surface will mask the low energy aluminum peak, preventing it from showing on the spectrum. The peak at $1400 \mathrm{eV}$ represents aluminum atoms which are 40 to $50 \AA$ below the surface.

Carbon appears at only one energy level, that being $272 \mathrm{eV}$. The height of the carbon peak roughly indicates the quantity of carbon on the surface; the larger the peak height, the more that is present. Although the peak height gives an indication of the quantity of carbon present at the surface, it gives no indication of the total thickness of the contamination. To measure the thickness, the surface of the die must be sputtered until the output spectrum shows only the underlying aluminum (and oxygen).

A survey was made before and after sputtering of each device cleaned to first show the presence of carbon and secondly to verify that all the carbon had been removed during the sputtering process. Table A-1 gives the results of each sputtering run. The average sputtered depth at each test point was used to produce the model of the plasma process. 
Table A-1. Auger Analysis Results for the Duplicated Box-Behnken Designed Experiment Indicating the Contamination Thickness Remaining After Cleaning at the Specified Parameters

\begin{tabular}{|c|c|c|c|c|c|c|c|}
\hline $\begin{array}{c}\text { POWER } \\
(\text { Watts })\end{array}$ & $\begin{array}{c}\text { TIME } \\
(\text { Min) }\end{array}$ & $\begin{array}{c}\text { PRESSURE } \\
(\text { Torr })\end{array}$ & $\begin{array}{c}\text { DEVICE 1 } \\
(\AA)\end{array}$ & $\begin{array}{c}\text { DEVICE 2 } \\
(\AA)\end{array}$ & $\begin{array}{c}\text { DEVICE 3 } \\
(\AA)\end{array}$ & $\begin{array}{c}\text { DEVICE 4 } \\
(\AA)\end{array}$ & $\begin{array}{c}\text { AVG. } \\
(\AA)\end{array}$ \\
\hline 50 & 5 & 0.7 & 235 & 220 & 225 & 280 & 240 \\
\hline 50 & 10 & 0.3 & 210 & 185 & 190 & 215 & 200 \\
\hline 50 & 10 & 1.1 & 220 & 195 & 180 & 205 & 200 \\
\hline 50 & 15 & 0.7 & 150 & 175 & 185 & 210 & 180 \\
\hline 100 & 5 & 0.3 & 200 & 190 & 180 & 200 & 190 \\
\hline 100 & 5 & 1.1 & 150 & 175 & 140 & 140 & 150 \\
\hline 100 & 10 & 0.7 & 80 & 95 & 100 & 105 & 95 \\
\hline 100 & 10 & 0.7 & 90 & 95 & 115 & 100 & 100 \\
\hline 100 & 10 & 0.7 & 110 & 90 & 110 & 90 & 100 \\
\hline 100 & 15 & 0.3 & 115 & 145 & 135 & 125 & 130 \\
\hline 100 & 15 & 1.1 & 80 & 85 & 85 & 90 & 85 \\
\hline 150 & 5 & 0.7 & 40 & 45 & 45 & 50 & 40 \\
\hline 150 & 10 & 0.3 & 20 & 25 & 25 & 30 & 25 \\
\hline 150 & 10 & 1.1 & 25 & 25 & 20 & 30 & 25 \\
\hline 150 & 15 & 0.7 & 30 & 25 & 35 & 30 & 30 \\
\hline
\end{tabular}


Table A-2. Auger Analysis Results of the Additional Data Required for the Second Full Factorial Study

\begin{tabular}{|c|c|c|c|c|c|}
\hline $\begin{array}{c}\text { POWER } \\
\text { (Watts })\end{array}$ & $\begin{array}{c}\text { TIME } \\
(\text { Min })\end{array}$ & $\begin{array}{c}\text { PRESSURE } \\
(\text { Torr })\end{array}$ & $\begin{array}{c}\text { DEVICE 1 } \\
(\AA)\end{array}$ & $\begin{array}{c}\text { DEVICE 2 } \\
(\AA)\end{array}$ & $\begin{array}{c}\text { AVG. } \\
(\AA)\end{array}$ \\
\hline 50 & 25 & 0.7 & 115 & 125 & 120 \\
\hline 100 & 25 & 0.7 & 25 & 25 & 25 \\
\hline 150 & 25 & 0.7 & 0 & 0 & 0 \\
\hline 200 & 5 & 0.7 & 0 & 0 & 0 \\
\hline 200 & 10 & 0.7 & 0 & 0 & 0 \\
\hline 200 & 15 & 0.7 & 0 & 0 & 0 \\
\hline 200 & 25 & 0.7 & 0 & 0 & 0 \\
\hline
\end{tabular}

\section{Sputtering Technique for Determining Carbon Depth}

To determine the thickness of contamination on the die surface, the Auger equipment was set to monitor the elements of aluminum and carbon. The system swept a two by two millimeter area and measured the number of electrons removed from those elements during each sweep. An argon beam was directed at the die to sputter through the surface material. After sputtering for six seconds (which is the minimum sputter time allowed by the equipment), another sweep was made of the surface to measure the electrons emitted by carbon and aluminum. This pattern of sputtering for six seconds and analyzing the surface continued until the measurement of carbon fell into the background noise of the equipment. The data collected between sputters was then regressed using Phi-Matlab software; a package written by Mathworks, Inc., designed specifically for the reduction of surface analysis data. The software package eliminates background noise and calculates the total sputter time to remove the carbon. Multiplying the sputter time with the sputter rate of $40 \mathrm{~A} / \mathrm{min}$ gave the thickness of the carbon contamination. 
Scale Factor: $7.119 \mathrm{kc} / \mathrm{s}$ offset: $-41.153 \mathrm{kc} / \mathrm{s}$

Ep: $3.00 \mathrm{kV}$ Ip: $0.0008 \mathrm{UA}$

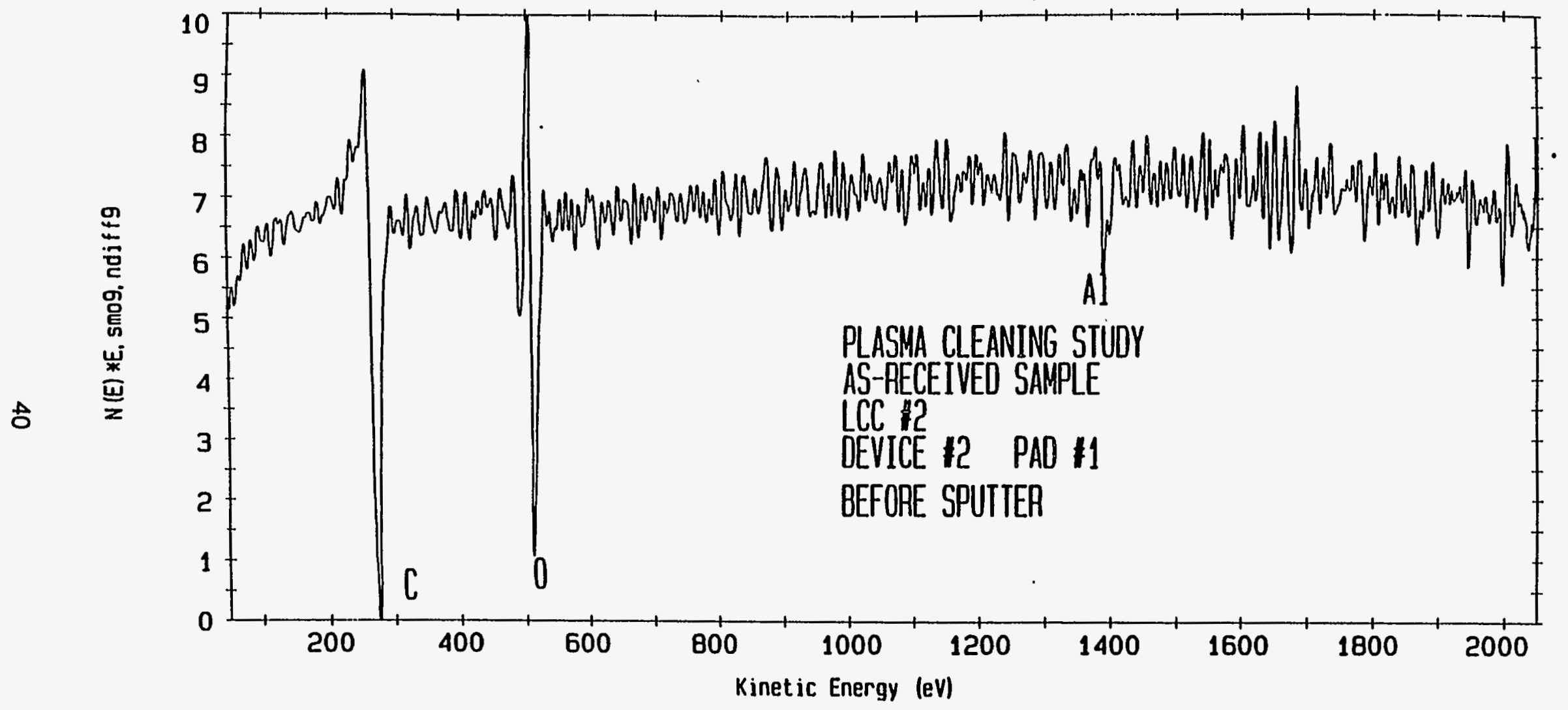

Figure A-1. Auger Spectrum of an Uncleaned Device 
Scale Factor: $235.911 \mathrm{kc} / \mathrm{s}$ of fset: $-1253.556 \mathrm{kc} / \mathrm{s}$

Ep: $3.00 \mathrm{kV}$ Ip: $0.0136 \mathrm{uA}$

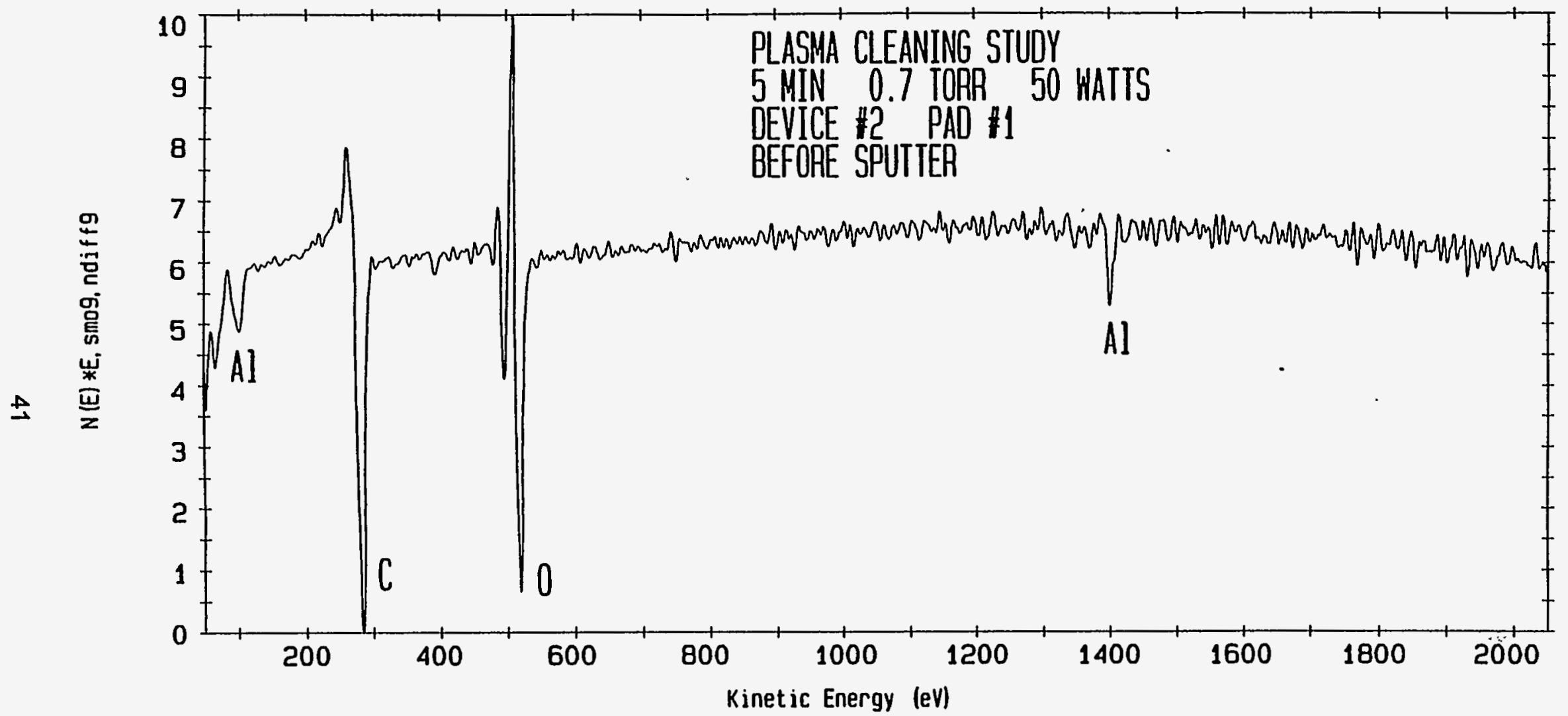

Figure A-2. Auger Spectrum of Device Cleaned 50 Watts, 5 Min, 0.7 Torr 
Scale Factor: $408.717 \mathrm{kc} / \mathrm{s}$ of fset: $-2171.978 \mathrm{kc} / \mathrm{s}$

Ep: $3.00 \mathrm{kV}$ Ip: $0.0160 \mathrm{uA}$

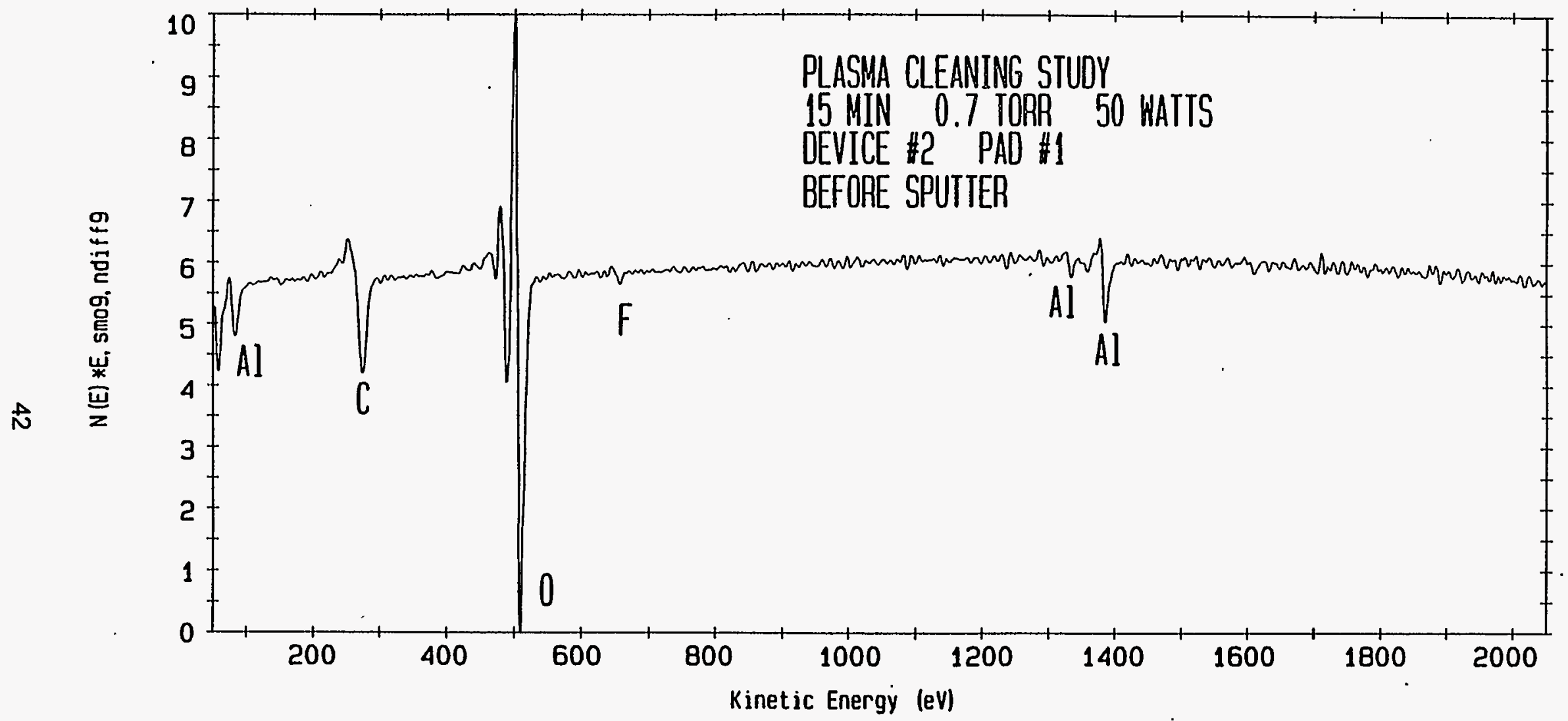

Figure A-3. Auger Spectrum of Device Cleaned 50 Watts, 15 Min, 0.7 Torr 
Scale Factor: $194.078 \mathrm{kc} / \mathrm{s}$ offset: $-1015.251 \mathrm{kc} / \mathrm{s}$

Ep: $3.00 \mathrm{kV}$ Ip: $0.0061 \mathrm{UA}$

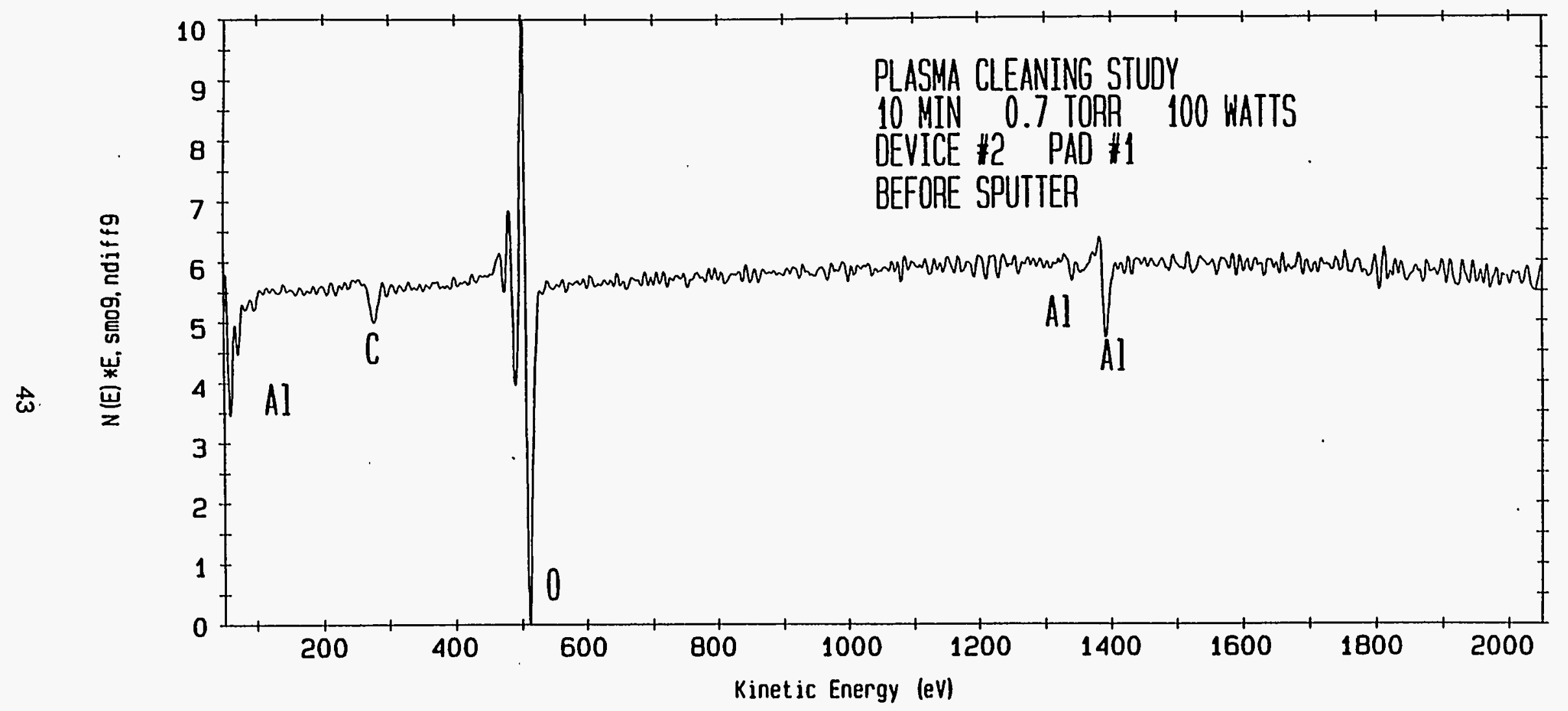

Figure A-4. Auger Spectrum of Device Cleaned 100 Watts, 10 Min, 0.7 Torr 


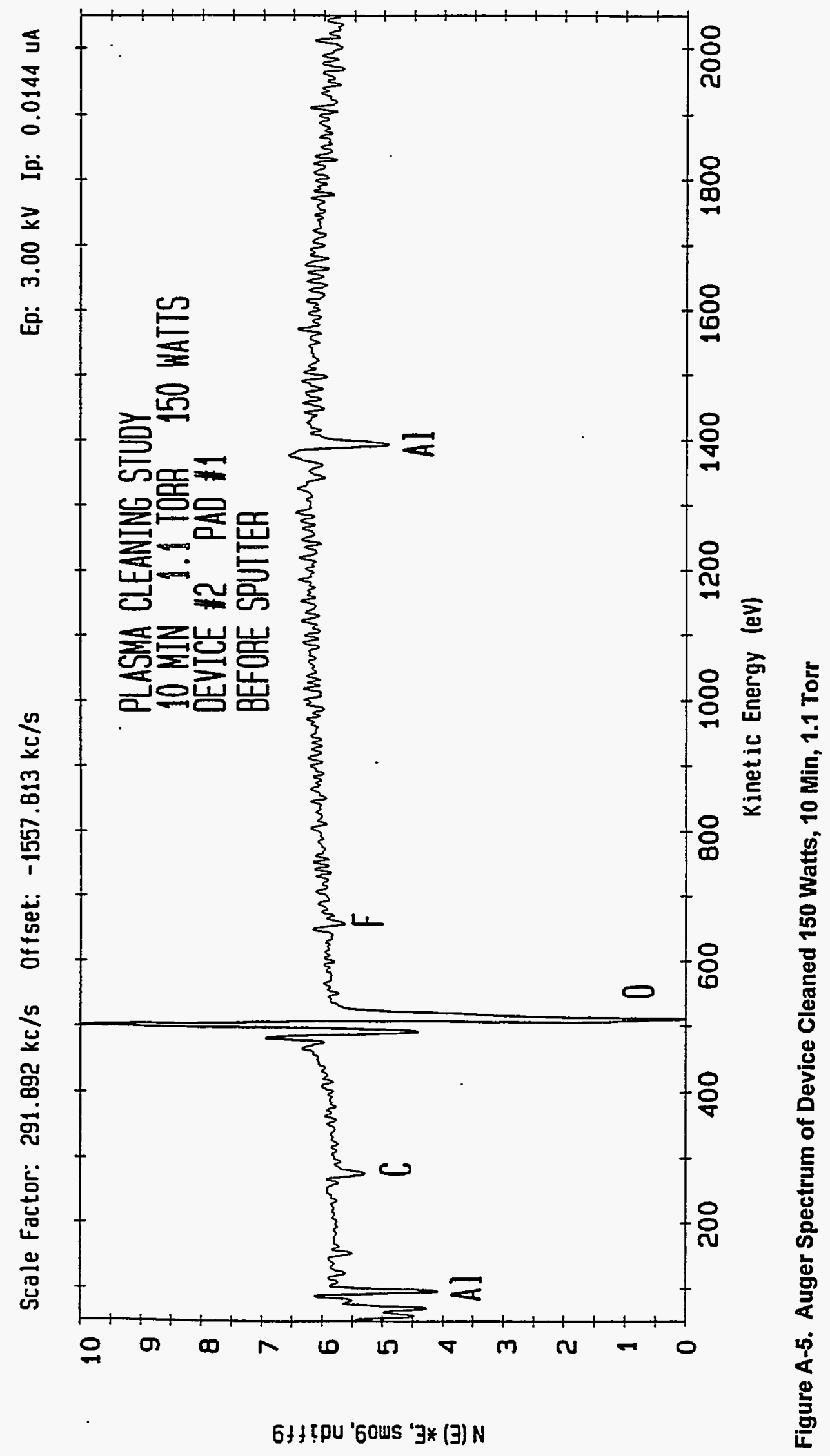


Scale Factor: $302.324 \mathrm{kc} / \mathrm{s}$ offset: $-1723.022 \mathrm{kc} / \mathrm{s}$

Ep: $3.00 \mathrm{kV}$ Ip: $0.0141 \mathrm{UA}$

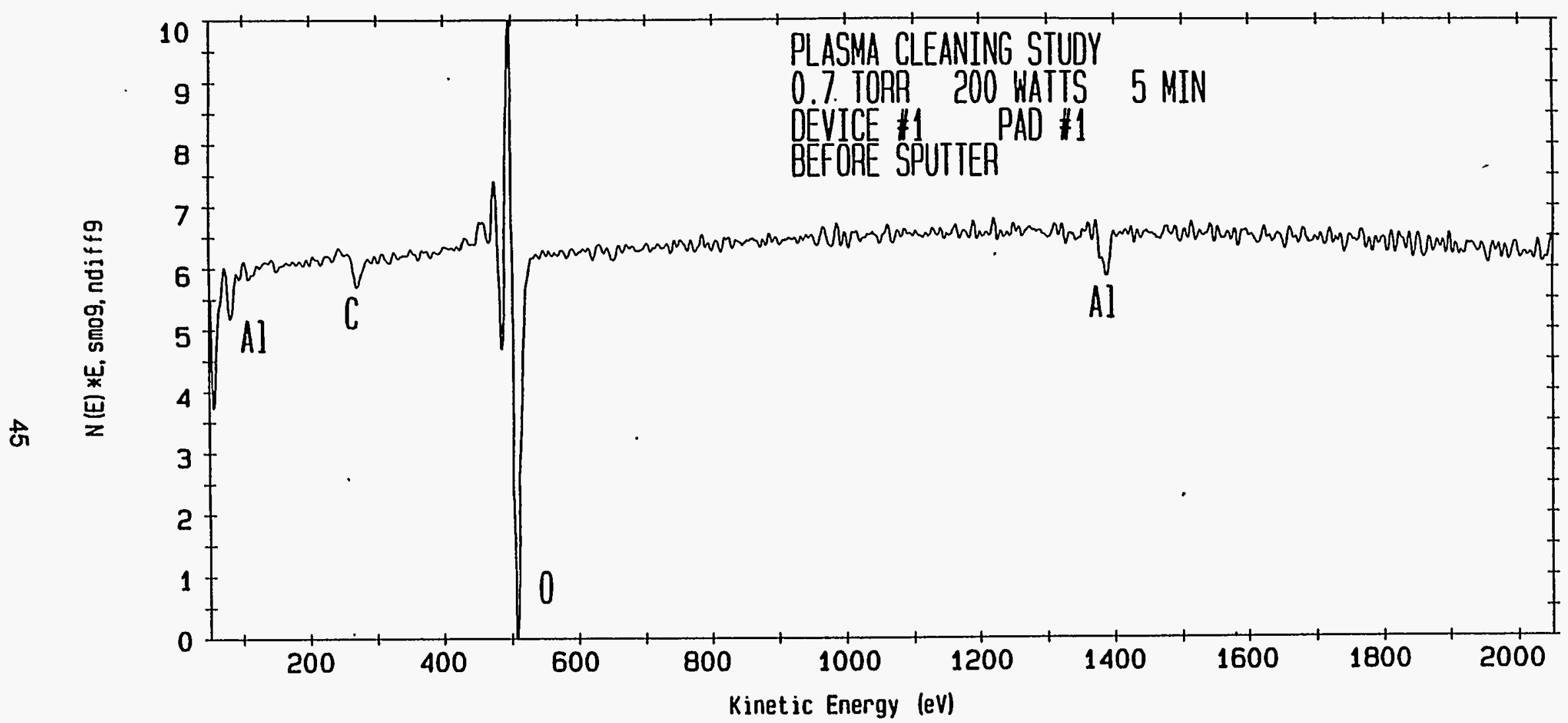

Figure A-6. Auger Spectrum of Device Cleaned 200 Watts, 5 Min, 0.7 Torr 


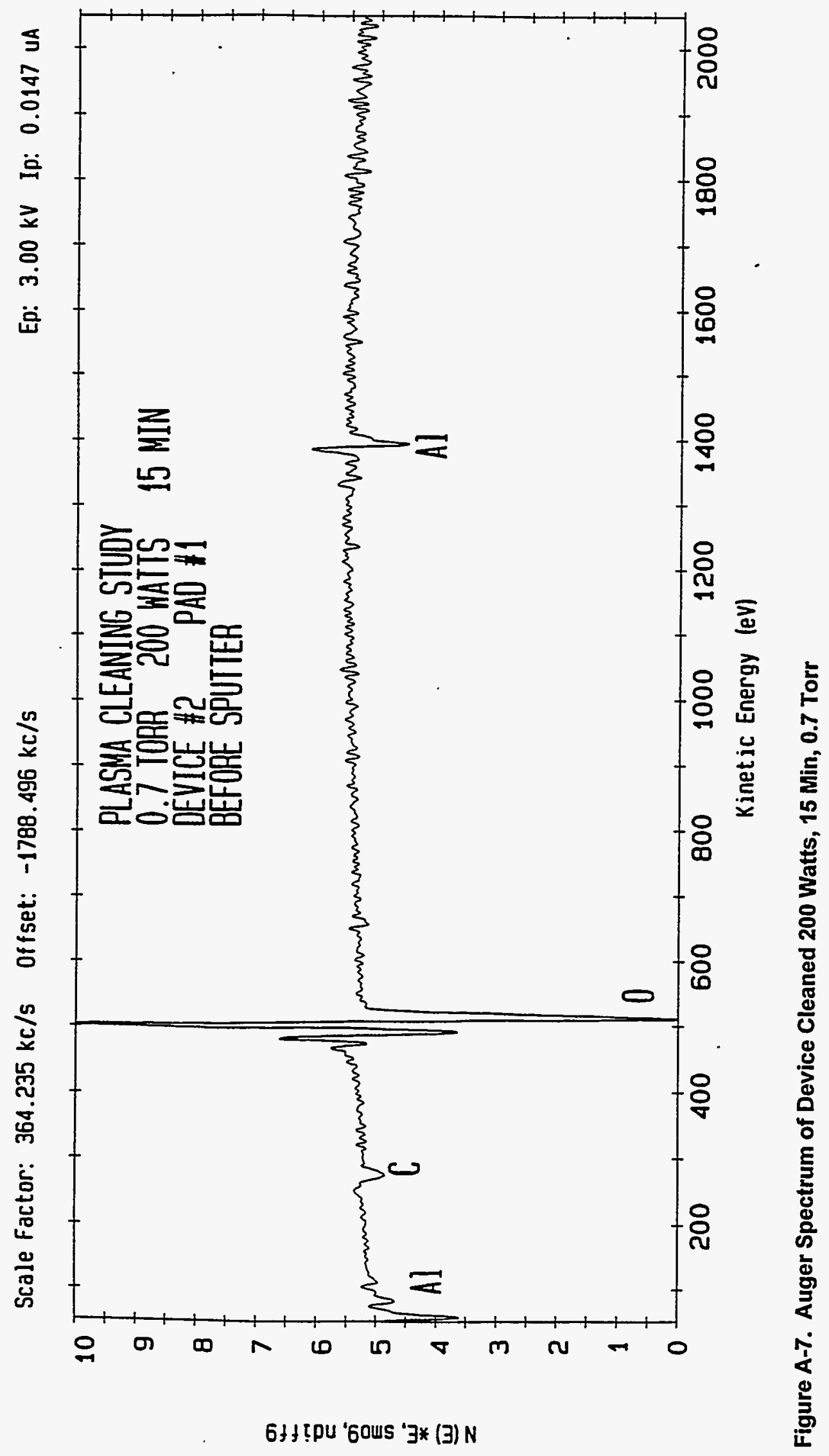




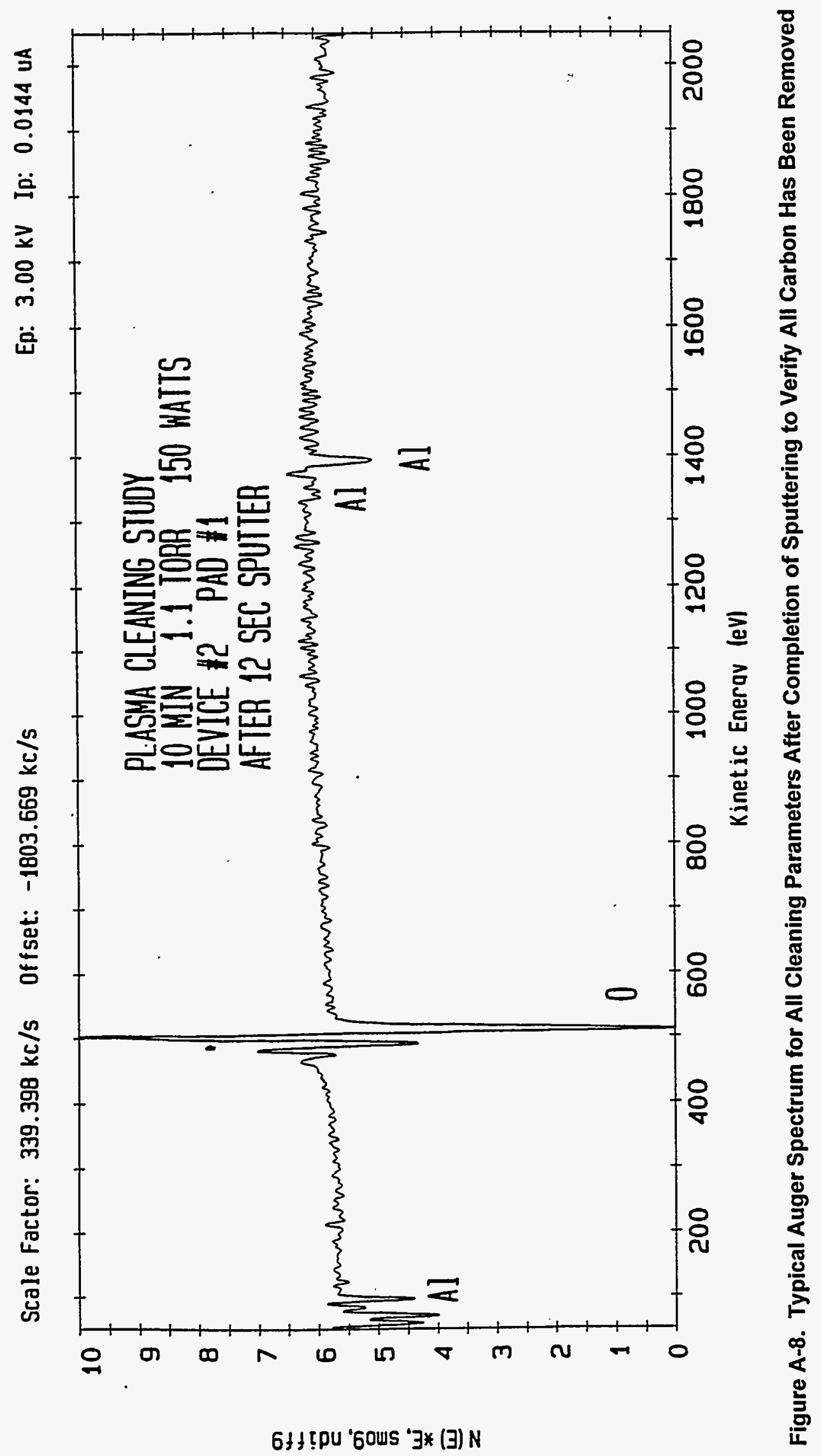




\section{Appendix B}

\section{Electrical Test Data}




\section{Electrical Test Data}

\section{Electrical Testing of Plasma-Cleaned Devices}

Testing of the bipolar transistors and diodes was done on the Lorlin Impact IV tester. The tester is programmed to pulse a specific voltage or current to each device for approximately 20 milliseconds and compare the resulting output with a circuit set at the upper specification limit. If the measured output compared to preset limits is higher, then the part is rejected. If the value falls below the limit, then the tester begins a routine to determine the value of the device. This routine, known as successive approximation, is similar to a root finding routine such as bisection. The routine compared the value of the devices with percentages of the comparison current (which is set at the limit) until a match is found. The value of the output on the device is usually found after eight to twelve iterations. Each device is tested independently.

The electrical test matrix for the bipolar transistors and diodes is given in Table B-1. Tests one through four were conducted on the diodes, tests five through nineteen were on the NPN transistors, and tests twenty through thirty three were on the PNP transistors. The test conditions listed in Table B-1 indicate how to power the devices during testing. The test limits are the maximum reading allowed before the part is considered electrically bad.

\section{Table B-1. Electrical Tests Performed on Diodes and Transistors}

\begin{tabular}{|c|c|c|c|c|}
\hline Test No. & Test Title & Test Condition & Test Limits & Notes \\
\hline 1 & $\mathbb{R}$ & $\mathrm{VR}=55 \mathrm{~V}$ & $75 n A$ & Reverse current on diode \\
\hline 2 & VF & $\mathrm{IF}=1 \mathrm{~mA}$ & $\begin{array}{l}0.5 \vee \text { MIN } \\
0.7 \vee \text { MAX }\end{array}$ & Forward voltage on diode \\
\hline 3 & VF & $\mathrm{IF}=10 \mathrm{~mA}$ & $0.8 \vee \operatorname{MAX}$ & Forward voltage on diode \\
\hline 4 & IR & $\mathrm{VR}=55 \mathrm{~V}$ & 75 nA MAX & repeat of test 1 \\
\hline 5 & ICBO & $V C B=-50 V$ & -10 nA MAX & $\begin{array}{l}\text { leakage current collector to } \\
\text { base for NPN transistor }\end{array}$ \\
\hline 6 & ICBO & $V C B=-70 \mathrm{~V}$ & -10 UA MAX & $\begin{array}{l}\text { leakage current collector to } \\
\text { base for NPN transistor }\end{array}$ \\
\hline 7 & ICES & VCE $=-50 \mathrm{~V}$ & $-10 n A M A X$ & $\begin{array}{l}\text { leakage current collector to } \\
\text { emitter for NPN transistor }\end{array}$ \\
\hline 8 & ICER & $\begin{array}{l}\mathrm{VCE}=-50 \mathrm{~V} \\
\mathrm{R}=1 \mathrm{KOHM}\end{array}$ & $-50 n A M A X$ & $\begin{array}{l}\text { leakage current collector to } \\
\text { emitter for NPN transistor }\end{array}$ \\
\hline 9 & IEBO & $\mathrm{VEB}=-5 \mathrm{~V}$ & $-2 n A M A X$ & $\begin{array}{l}\text { leakage current emitter to } \\
\text { base for NPN transistor }\end{array}$ \\
\hline 10 & VCES & $\begin{array}{l}I C=-10 \mathrm{~mA} \\
\mathrm{IB}=-500 \mathrm{uA}\end{array}$ & $-0.3 \vee \operatorname{MAX}$ & $\begin{array}{l}\text { voltage from collector to } \\
\text { emitter for NPN transistor }\end{array}$ \\
\hline 11 & VBES & $\begin{array}{l}I C=-10 \mathrm{~mA} \\
\mathrm{IB}=-500 \mathrm{uA}\end{array}$ & $\begin{array}{l}-0.7 \text { V MIN } \\
-0.9 \vee \operatorname{MAX} \\
\end{array}$ & $\begin{array}{l}\text { voltage from base to emitter } \\
\text { for NPN transistor }\end{array}$ \\
\hline 12 & VBEON & $\begin{array}{l}\mathrm{VCE}=-5 \mathrm{~V} \\
\mathrm{IC}=-5 \mathrm{~mA}\end{array}$ & $\begin{array}{l}-0.35 \vee \text { MIN } \\
-0.95 \text { V MAX }\end{array}$ & $\begin{array}{l}\text { voltage base to emitter for } \\
\text { NPN transistor }\end{array}$ \\
\hline
\end{tabular}




\begin{tabular}{|c|c|c|c|c|}
\hline 13 & VBEON & $\begin{array}{l}V C E=-5 V \\
I C=-20 \mathrm{~mA}\end{array}$ & $\begin{array}{l}-0.35 \vee \text { MIN } \\
-0.95 \vee \text { MAX }\end{array}$ & $\begin{array}{l}\text { voltage base to emitter for } \\
\text { NPN transistor }\end{array}$ \\
\hline 14 & $1+\mathrm{HFE}$ & $\begin{array}{c}V C E=-5 \\
V I C=-10 \mathrm{~mA}\end{array}$ & $\begin{array}{l}101 \mathrm{MIN} \\
301 \mathrm{MAX}\end{array}$ & gain for NPN transistor \\
\hline 15 & HFE & $\begin{array}{l}\mathrm{VCE}=-5 \mathrm{~V} \\
\mathrm{IC}=-500 \mathrm{uA}\end{array}$ & $\begin{array}{l}150 \text { MIN } \\
450 \text { MAX }\end{array}$ & gain for NPN transistor \\
\hline 16 & HFE & $\begin{array}{l}\text { VCE }=-5 \mathrm{~V} \\
I C=-10 \mathrm{~mA}\end{array}$ & $\begin{array}{l}100 \mathrm{MIN} \\
400 \mathrm{MAX} \\
\end{array}$ & gain for NPN transistor \\
\hline 17 & HFE & $\begin{array}{l}\text { VCE }=-5 \mathrm{~V} \\
I C=-20 \mathrm{~mA} \\
\end{array}$ & $\begin{array}{c}20 \mathrm{MIN} \\
400 \mathrm{MAX} \\
\end{array}$ & gain for NPN transistor \\
\hline 18 & ICBO & $\mathrm{VCB}=-50 \mathrm{~V}$ & -10 nA MAX & Repeat of test 5 \\
\hline 19 & IEBO & $V C B=-5 V$ & -2 nA MAX & Repeat of test 6 \\
\hline 20 & ICBO & $\mathrm{VCB}=20 \mathrm{~V}$ & $10 \mathrm{nAMAX}$ & $\begin{array}{l}\text { leakage current collector to } \\
\text { base for PNP transistor }\end{array}$ \\
\hline 21 & IEBO & $\mathrm{VEB}=4 \mathrm{~V}$ & 250 nAMAX & $\begin{array}{l}\text { leakage current emitter to } \\
\text { base for PNP transistor }\end{array}$ \\
\hline 22 & ICER & $\begin{array}{l}\mathrm{VCE}=13 \mathrm{~V} \\
\mathrm{R}=1 \mathrm{KOHM}\end{array}$ & 10 nA MAX & $\begin{array}{l}\text { leakage current collector to } \\
\text { emitter for PNP transistor }\end{array}$ \\
\hline 23 & HFE & $\begin{array}{l}\mathrm{VCE}=5 \mathrm{~V} \\
\mathrm{IC}=1 \mathrm{~mA}\end{array}$ & $\begin{array}{l}30 \mathrm{MIN} \\
500 \mathrm{MAX}\end{array}$ & gain for PNP transistor \\
\hline 24 & HFE & $\begin{array}{l}\mathrm{VCE}=5 \mathrm{~V} \\
\mathrm{IC}=10 \mathrm{~mA}\end{array}$ & $\begin{array}{c}40 \mathrm{MIN} \\
500 \mathrm{MAX}\end{array}$ & gain for PNP transistor \\
\hline 25 & HFE & $\begin{array}{c}\mathrm{VCE}=5 \mathrm{~V} \\
\mathrm{IC}=100 \mathrm{~mA}\end{array}$ & $\begin{array}{c}20 \mathrm{MIN} \\
500 \mathrm{MAX}\end{array}$ & gain for PNP transistor \\
\hline 26 & VCES & $\begin{array}{l}\mathrm{IC}=10 \mathrm{~mA} \\
\mathrm{IB}=1 \mathrm{~mA}\end{array}$ & $0.2 \vee \operatorname{MAX}$ & $\begin{array}{l}\text { voltage from collector to } \\
\text { emitter for PNP transistor }\end{array}$ \\
\hline 27 & VBES & $\begin{array}{l}\mathrm{IC}=10 \mathrm{~mA} \\
\mathrm{IB}=1 \mathrm{~mA}\end{array}$ & $\begin{array}{l}0.7 \vee \text { MIN } \\
0.9 \vee \text { MAX }\end{array}$ & $\begin{array}{l}\text { voltage from base to emitter } \\
\text { for PNP transistor }\end{array}$ \\
\hline 28 & VCES & $\begin{array}{l}\mathrm{IC}=100 \mathrm{~mA} \\
\mathrm{IB}=10 \mathrm{~mA}\end{array}$ & $0.55 \vee \mathrm{MAX}$ & $\begin{array}{l}\text { voltage from collector to } \\
\text { emitter for PNP transistor }\end{array}$ \\
\hline 29 & VBES & $\begin{array}{l}\mathrm{IC}=100 \mathrm{~mA} \\
\mathrm{IB}=10 \mathrm{~mA}\end{array}$ & $\begin{array}{l}0.8 \vee \mathrm{MIN} \\
1.2 \mathrm{~V} \text { MAX }\end{array}$ & $\begin{array}{l}\text { voltage from base to emitter } \\
\text { for PNP transistor }\end{array}$ \\
\hline 30 & VBEON & $\begin{array}{l}\mathrm{VCE}=5 \mathrm{~V} \\
\mathrm{IC}=5 \mathrm{~mA}\end{array}$ & $\begin{array}{l}0.35 \vee \text { MIN } \\
0.95 \vee \text { MAX }\end{array}$ & $\begin{array}{l}\text { voltage from base to emitter } \\
\text { for PNP transistor }\end{array}$ \\
\hline 31 & VBEON & $\begin{array}{l}\text { VCE }=5 \mathrm{~V} \\
\mathrm{IC}=20 \mathrm{~mA}\end{array}$ & $\begin{array}{l}0.35 \vee \text { MIN } \\
0.95 \vee \text { MAX }\end{array}$ & $\begin{array}{l}\text { voltage from base to emitter } \\
\text { for PNP transistor }\end{array}$ \\
\hline 32 & ICBO & $\mathrm{VCB}=20 \mathrm{~V}$ & 10 nA MAX & Repeat of test 20 \\
\hline 33 & IEBO & VEB $=4 \mathrm{~V}$ & $250 n A M A X$ & Repeat of test 21 \\
\hline
\end{tabular}

The purpose of the repeat tests $(4,18,19,32,33)$ was to ensure the tester caused no damage to the devices. 
The increase in the leakage current for the diodes and transistors resulting from an exposure to the oxygen plasma process can be seen in Tábles B-2 to B-4. Statistical analysis of the data in Tables B-2 to $B-4$ was run to determine if a significant difference among the tables of data existed. Figure B-1 shows the statistical comparison of the increased transistor leakage current between the collector and the base among the different plasma power settings. Figure B-2 is a statistical comparison of the increased diode leakage current among the different plasma power settings. The Box and Whisker plots show the data average, range, and standard deviation for each group individually. The ANOVA table imbedded in Figures B-1 and B-2 prove (by the $P$-value being greater than 0.05 ) that there is no statistically significant difference in the sets of data collected at each of the plasma power settings. Therefore, since all values of leakage current remained well below the specification limits given in Table B-1, any of the power settings studied would be acceptable for production cleaning. 
Table B-2. Increase in Leakage Current for Bipolar Transistors and Diodes After Oxygen Plasma Cleaning at 150 Watts, 0.7 Torr, 15 Minutes

\begin{tabular}{|l|c|c|c|c|c|c|c|c|}
\hline & IR diode & ICBO50 & ICBO70 & ICES50 & ICER50 & IEBO5 & ICBO20 & ICER13 \\
\hline & 5.48 & 0.52 & 0.75 & 0.78 & 0.77 & 0.00 & 0.76 & 0.58 \\
\hline & 8.96 & 2.57 & 3.20 & 2.98 & 2.92 & 0.35 & 1.31 & 1.80 \\
\hline & 7.24 & 4.15 & 4.90 & 4.04 & 3.57 & 0.72 & 2.46 & 2.49 \\
\hline & 6.16 & 1.05 & 1.30 & 1.56 & 1.49 & 0.89 & 5.52 & 1.26 \\
\hline & 5.10 & 0.75 & 0.95 & 0.88 & 0.74 & 0.00 & 0.69 & 0.96 \\
\hline & 4.34 & 0.88 & 0.95 & 1.15 & 1.22 & 0.00 & 1.34 & 0.74 \\
\hline & 4.16 & 2.41 & 2.80 & 2.26 & 2.32 & 0.06 & 1.24 & 0.75 \\
\hline & 3.83 & 0.86 & 1.05 & 1.41 & 1.38 & 0.00 & 0.81 & 0.91 \\
\hline & 7.09 & 0.83 & 1.00 & 1.14 & 1.23 & 0.00 & 1.25 & 0.96 \\
\hline & 5.66 & 1.02 & 1.35 & 1.05 & 1.15 & 0.04 & 0.86 & 1.09 \\
\hline & 3.46 & 0.62 & 0.70 & 1.31 & 1.20 & 0.20 & 0.73 & 1.07 \\
\hline & 8.46 & 1.49 & 1.90 & 1.42 & 1.25 & 0.40 & 1.85 & 0.70 \\
\hline & 6.84 & 2.26 & 2.95 & 2.72 & 2.56 & 0.60 & 2.27 & 1.39 \\
\hline & 5.02 & 0.86 & 0.95 & 4.36 & 3.86 & 0.26 & 0.17 & 2.51 \\
\hline & 3.90 & 0.96 & 1.20 & 8.71 & 8.07 & 0.08 & 0.01 & 0.63 \\
\hline & 2.93 & 0.94 & 1.85 & 1.31 & 1.12 & 0.13 & 0.83 & 1.17 \\
\hline & 5.52 & 0.61 & 2.10 & 1.93 & 1.80 & 0.16 & 0.81 & 1.16 \\
\hline & 5.50 & 0.69 & 0.70 & 1.86 & 1.69 & 0.24 & 0.88 & 0.87 \\
\hline & 4.99 & 1.49 & 2.15 & 1.43 & 2.37 & 0.14 & 1.34 & 0.82 \\
\hline & 4.78 & & & 2.59 & 1.25 & 0.19 & 1.11 & 1.13 \\
\hline & 5.47 & 1.31 & 1.72 & 2.32 & 2.17 & 0.23 & 1.39 & 1.18 \\
\hline AVG. & 1.60 & 0.92 & 1.10 & 1.83 & 1.67 & 0.26 & 1.15 & 0.54 \\
\hline & & & & & &
\end{tabular}


Table B-3. Increase in Leakage Current for Bipolar Transistors and Diodes After Oxygen Plasma Cleaning at 100 Watts, 0.7 Torr, 15 Minutes

\begin{tabular}{|l|c|c|c|c|c|c|c|c|}
\hline & IR diode & ICBO50 & ICBO70 & ICES50 & ICER50 & IEBO5 & ICBO20 & ICER13 \\
\hline & 5.92 & 0.95 & 1.15 & 1.66 & 1.66 & 0.13 & 1.43 & 1.09 \\
\hline & 6.57 & 0.89 & 1.10 & 1.14 & 1.15 & 0.23 & 2.34 & 1.89 \\
\hline & 11.15 & 2.71 & 3.70 & 3.20 & 3.48 & 0.96 & 3.80 & 4.62 \\
\hline & 6.61 & 2.13 & 2.85 & 2.59 & 2.68 & 1.34 & 3.48 & 3.16 \\
\hline & 8.38 & 2.67 & 3.25 & 4.08 & 4.16 & 0.55 & 3.58 & 3.54 \\
\hline & 12.78 & 0.92 & 1.10 & 1.51 & 1.50 & 0.13 & 0.96 & 0.85 \\
\hline & 3.76 & 0.80 & 0.95 & 1.00 & 0.98 & 0.10 & 6.73 & 2.87 \\
\hline & 5.83 & 2.24 & 2.90 & 3.06 & 3.20 & 0.37 & 6.01 & 2.80 \\
\hline & 4.98 & 1.96 & 2.55 & 2.30 & 2.24 & 0.23 & 3.42 & $3.84 \cdots$ \\
\hline & 2.82 & 0.73 & 0.85 & 1.00 & 0.96 & 0.07 & 1.12 & 1.22 \\
\hline & 2.83 & 2.52 & 1.95 & 3.32 & 3.08 & 0.18 & 0.91 & 1.51 \\
\hline & 5.52 & 1.61 & 2.40 & 2.33 & 2.11 & 0.11 & 2.54 & 1.90 \\
\hline & 8.99 & 1.65 & 1.65 & 2.84 & 2.73 & 0.96 & 3.92 & 4.62 \\
\hline & 8.06 & 1.28 & 8.50 & 2.02 & 1.80 & 0.46 & 2.80 & $3.54 \cdots$ \\
\hline & 6.59 & 7.03 & 1.45 & 8.10 & 7.66 & 1.35 & 3.29 & 4.29 \\
\hline & 3.55 & 1.16 & 3.30 & 1.87 & 1.68 & 0.00 & 0.86 & 1.02 \\
\hline & 6.77 & 3.35 & 4.50 & 2.47 & 1.99 & 0.00 & 4.30 & 3.34 \\
\hline & 10.82 & 3.27 & 2.60 & 6.53 & 6.37 & 1.40 & 2.42 & 4.84 \\
\hline & 4.87 & 2.19 & 1.35 & 3.64 & 3.40 & 0.53 & 2.83 & 3.22 \\
\hline & 4.67 & 1.16 & 2.10 & 1.65 & 1.45 & 0.00 & 1.19 & 1.02 \\
\hline & 6.57 & 1.66 & 1.20 & 2.41 & 2.40 & 0.33 & 2.89 & 2.76 \\
\hline & 2.76 & 1.01 & 4.25 & 1.46 & 1.46 & 0.16 & 1.63 & 1.35 \\
\hline
\end{tabular}


Table B-4. Increase in Leakage Current for Bipolar Transistors and Diodes After Oxygen Plasma Cleaning at 200 Watts, 0.7 Torr, 15 Minutes

\begin{tabular}{|l|c|c|c|c|c|c|c|c|}
\hline & IR diode & ICBO50 & ICBO70 & ICES50 & ICER50 & IEBO5 & ICBO20 & ICER13 \\
\hline & 5.97 & 1.33 & 1.75 & 1.60 & 1.53 & 0.10 & 1.65 & 1.31 \\
\hline & 10.78 & 4.71 & 6.50 & 6.60 & 6.58 & 1.14 & 4.35 & 5.07 \\
\hline & 6.98 & 2.19 & 2.85 & 3.27 & 3.05 & 0.51 & 1.61 & 1.35 \\
\hline & 18.32 & 2.53 & 3.60 & 4.97 & 4.92 & 0.83 & 2.05 & 1.95 \\
\hline & 3.86 & 1.43 & 1.65 & 1.77 & 1.62 & 0.19 & 1.69 & 1.41 \\
\hline & 5.24 & 1.36 & 1.80 & 2.13 & 1.91 & 0.00 & 1.85 & 1.44 \\
\hline & 10.95 & 5.49 & 7.40 & 8.65 & 8.57 & 1.46 & -0.99 & 0.28 \\
\hline & 4.08 & 1.33 & 1.70 & 2.54 & 2.36 & 0.31 & 1.71 & 1.49 \\
\hline & 5.48 & 4.27 & 5.55 & 5.52 & 6.00 & 0.62 & 2.85 & 2.68 \\
\hline & 3.13 & 1.08 & 1.35 & 1.74 & 1.54 & 0.00 & 1.25 & 1.04 \\
\hline & & 0.75 & 1.00 & 0.95 & 0.90 & 0.08 & & \\
\hline & & 2.39 & 3.15 & 3.34 & 3.46 & 0.47 & & \\
\hline & & 1.27 & 1.65 & 1.66 & 1.60 & 0.21 & & \\
\hline & & 1.26 & 1.45 & 1.74 & 1.68 & 0.18 & & \\
\hline & & 0.95 & 1.15 & 1.13 & 1.04 & 0.10 & & \\
\hline & & 1.11 & 1.35 & 1.66 & 1.51 & 0.01 & & \\
\hline & & 3.28 & 4.60 & 5.48 & 5.61 & 0.01 & & \\
\hline & & 1.35 & 1.65 & 2.36 & 2.22 & 0.30 & & \\
\hline & & 3.84 & 4.90 & 5.42 & 5.17 & 0.80 & & \\
\hline & & 0.70 & 1.00 & 1.21 & 1.09 & 0.00 & & 1.80 \\
\hline AVG. & 7.48 & 2.13 & 2.80 & 3.19 & 3.12 & 0.41 & 1.80 \\
\hline
\end{tabular}




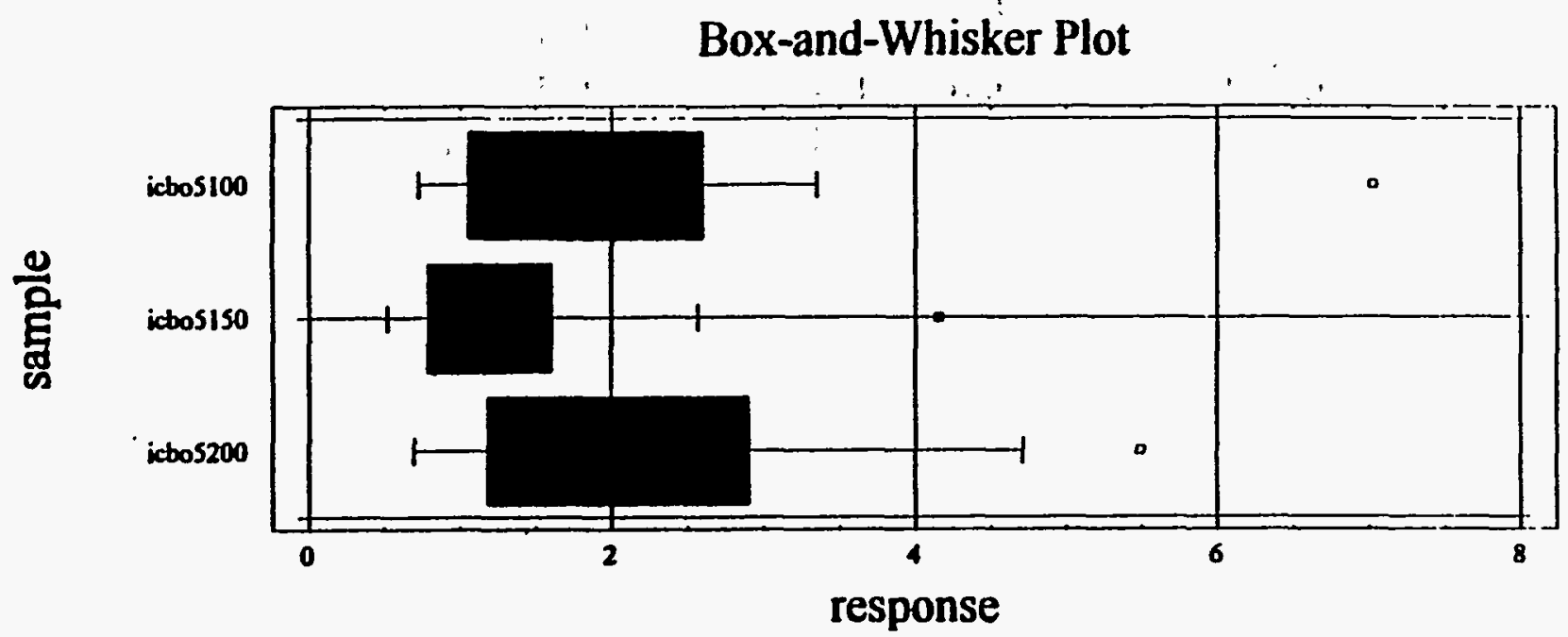

Analysis of Variance

\begin{tabular}{lccccc} 
Source & Sum of Squares & Df & Mean Square & E-Ratio & P-Value \\
\hline Between groups & 7.79092 & 2 & 3.89546 & 2.38 & 0.1015 \\
Within groups & 93.218 & 57 & 1.6354 & & \\
\hline Total (Corr.) & 101.009 & 59 & &
\end{tabular}

Table of Means

with 95.0 percent LSV intervals

\begin{tabular}{|c|c|c|c|c|c|c|}
\hline & Count & Mean & $\begin{array}{l}\text { stnd. error } \\
\text { (pooled s) }\end{array}$ & Lower limit & Upper & I imit \\
\hline $\begin{array}{l}\text { icbos } 11100 \\
\text { icbus } 150 \\
\text { icbos } 200\end{array}$ & $\begin{array}{l}20 \\
20 \\
20\end{array}$ & $\begin{array}{l}2.061 \\
1.334 \\
2.131\end{array}$ & $\begin{array}{l}0.285955 \\
0.285955 \\
0.285955\end{array}$ & $\begin{array}{r}1.6561 \\
\times \quad 0.929099 \\
1.7261\end{array}$ & & $\begin{array}{l}.1649 \\
1.1389 \\
2.4154\end{array}$ \\
\hline
\end{tabular}

Tulal

60

1.842

Figure B-1. Statistical Analysis of Transistor Leakage Current (ICBO) for Parts Exposed to Plasma Powers of 100, 150, and 200 Watts 


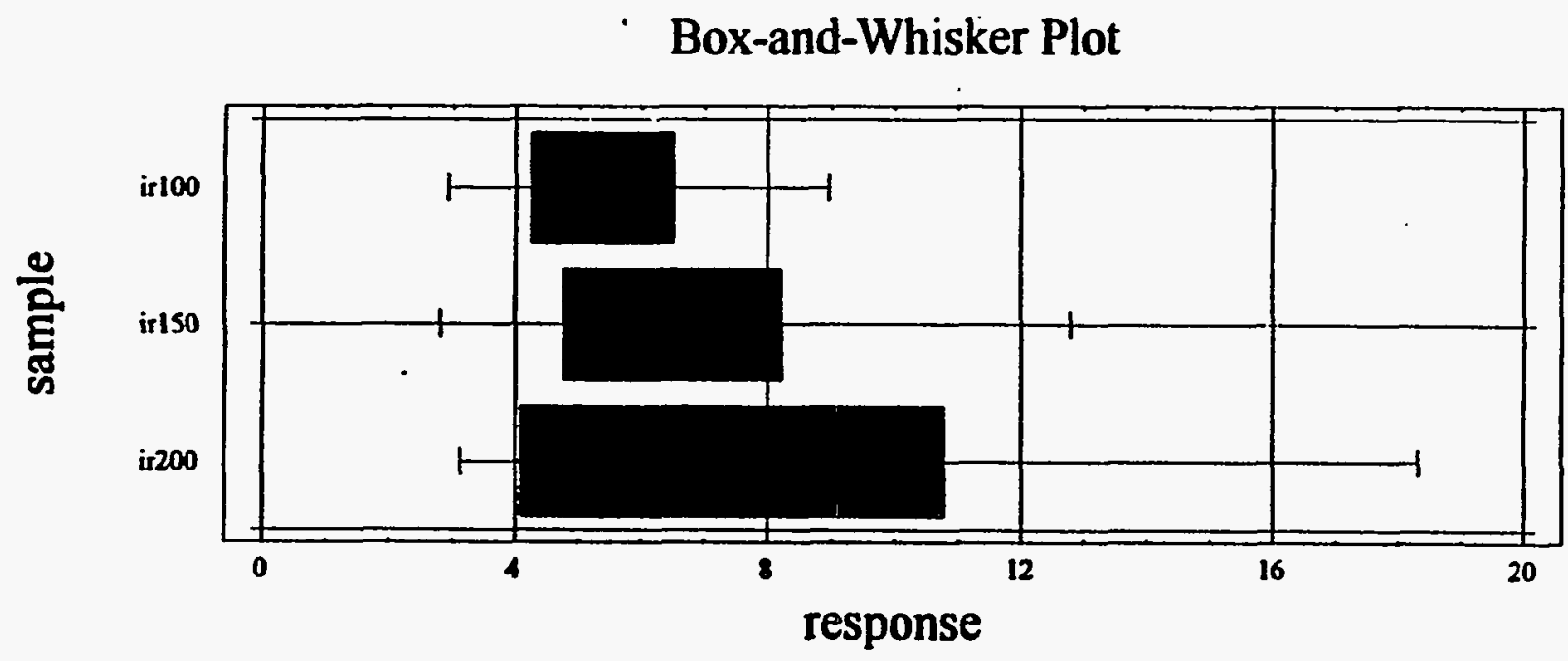

Analysis of Variance

\begin{tabular}{|c|c|c|c|c|c|}
\hline Source & Sum of Squares & Df & Mean Square & F-Ratio & P-Value \\
\hline $\begin{array}{l}\text { Between groups } \\
\text { within groups }\end{array}$ & $\begin{array}{r}29.132 \\
389.691\end{array}$ & $\begin{array}{r}2 \\
47\end{array}$ & $\begin{array}{l}14.566 \\
8.2913\end{array}$ & 1.76 & 0.1837 \\
\hline
\end{tabular}

Table of Means

with 95.0 percent LSD intervals

\begin{tabular}{|c|c|c|c|c|c|}
\hline & Count & Mean & $\begin{array}{l}\text { Stnd. error } \\
\text { (pooled s) }\end{array}$ & Lower I imit & Upper 1 imit \\
\hline $\begin{array}{l}\text { ir } 100 \\
\text { is } 150 \\
\text { i } r 200\end{array}$ & $\begin{array}{l}20 \\
20 \\
10\end{array}$ & $\begin{array}{r}5.471 \\
6.5735 \\
7.479\end{array}$ & $\begin{array}{l}0.643867 \\
0.643867 \\
0.910566\end{array}$ & $\begin{array}{r}4.55509 \\
5.65759 \\
6.1837\end{array}$ & $\begin{array}{r}6.38691 \\
7.48941 \\
0.7743\end{array}$ \\
\hline
\end{tabular}

Tot a 1

50

6.3136

Figure B-2. Statistical Analysis of Diode Leakage Current for Parts Exposed to Plasma Powers of 100,150 , and 200 Watts 